\title{
The Arabidopsis Patatin-Like Protein 2 (PLP2) Plays an Essential Role in Cell Death Execution and Differentially Affects Biosynthesis of Oxylipins and Resistance to Pathogens
}

\author{
Sylvain La Camera, ${ }^{1}$ Claudine Balagué, ${ }^{2}$ Cornelia Göbel, ${ }^{3}$ Pierrette Geoffroy, ${ }^{1}$ Michel Legrand, ${ }^{1}$ \\ Ivo Feussner, ${ }^{3}$ Dominique Roby, ${ }^{2}$ and Thierry Heitz ${ }^{1}$ \\ ${ }^{1}$ Institut de Biologie Moléculaire des Plantes du CNRS, UPR 2357, conventionné avec l'Université Louis Pasteur, 12 rue du \\ Général Zimmer, F-67084 Strasbourg Cedex, France; ${ }^{2}$ Laboratoire des Interactions Plantes-Microorganismes (LIPM), UMR \\ CNRS-INRA 2594/441, BP 52627, F-31320 Castanet-Tolosan Cedex, France; ${ }^{3}$ Institute for Plant Sciences, \\ Georg-August-University, Justus-von-Liebig-Weg 11, D-37077 Goettingen, Germany
}

Submitted 23 October 2008. Accepted 23 December 2008.

\begin{abstract}
We previously reported that patatin-like protein 2 (PLP2), a pathogen-induced patatin-like lipid acyl hydrolase, promotes cell death and negatively affects Arabidopsis resistance to the fungus Botrytis cinerea and to the bacteria Pseudomonas syringae. We show here that, on the contrary, PLP2 contributes to resistance to Cucumber mosaic virus, an obligate parasite inducing the hypersensitive response. These contrasted impacts on different pathosystems were also reflected by differential effects on defense gene induction. To examine a possible link between PLP2 lipolytic activity and oxylipin metabolism, gene expression profiling was performed and identified $B$. cinerea among these pathogens as the strongest inducer of most oxylipin biosynthetic genes. Quantitative oxylipin profiling in wild-type and PLP2-modified, Botrytis-challenged plants established the massive accumulation of oxidized fatty acid derivatives in infected leaves. Several compounds previously described as modulating plant tissue damage and issued from the $\alpha$-dioxygenase pathway were found to accumulate in a PLP2-dependent manner. Finally, the contribution of PLP2 to genetically controlled cell death was evaluated using PLP2-silenced or overexpressing plants crossed with the lesion mimic mutant vascular-associated death 1 (vad1). Phenotypic analysis of double-mutant progeny showed that PLP2 expression strongly promotes necrotic symptoms in vad1 leaves. Collectively, our data indicate that PLP2 is an integral component of the plant cell death execution machinery, possibly providing fatty acid precursors for the biosynthesis of specific oxylipins and differentially affecting resistance to pathogens with distinct lifestyles.
\end{abstract}

S. La Camera, C. Balagué, and C. Göbel made an equal contribution to this work.

Corresponding author: Thierry Heitz; Telephone: +33 388417 280; Fax: +33 388614 442; E-mail: Thierry.Heitz@ibmp-ulp.u-strasbg.fr

Present address of Sylvain La Camera: Department of Plant Biology, Université de Fribourg, 3, rue Albert Gockel, CH-1700, Fribourg, Switzerland.

* The $\boldsymbol{e}$-Xtra logo stands for "electronic extra" and indicates that one supplementary table and three supplementary figures are published online. Figures 1 and 6 also appear in color online.
Plant defense responses to pathogen attack are based on cellular and biochemical reprogramming to confine the intruder into a locally unfavorable environment. Two hallmarks of induced plant resistance against microbes are the triggering of host cell death at the infection site (Greenberg and Yao 2004) and the intricate deployment of defense genes and metabolic pathways (La Camera et al. 2004). Because the formation of necrotic lesions is tightly correlated with the intense upregulation of defensive genes in the surrounding living tissue, the relative contributions of these two components of defense to resistance is not easy to assess. In the case of race-specific recognition of biotrophic pathogens, the cell death process is largely programmed by host components to activate a localized cell suicide known as the hypersensitive response (HR) (Mur et al. 2008). The genetic control of this program is best exemplified in lesion mimic mutants (LMM) with aberrant regulation of cell death (Lorrain et al. 2003). The initiation and signaling steps of HR-type cell death that commit the cells to die are still poorly characterized. These early decision-making events precede an execution phase that culminates in the coordinated morphological collapse, orchestrated by host-encoded lytic enzyme sets that dismantle cellular organization (Jones 2001). In this context, LMM constitute useful models for the identification of components of early steps of these cell death program, either implicated in cell death initiation through the characterization of initiation mutants or involved in the limitation or propagation of cell death using the propagation mutants (Lorrain et al. 2003). The vascular-associated cell death 1 (vad1) mutant, which exhibits light conditional appearance of propagative HR-like lesions along the vascular system, is affected in defense and resistance mechanisms to bacterial pathogens and may be a good candidate as a potential regulator of cell death. In addition, it is also believed that dying cells are a source of signals for the activation of defense genes and pathways in neighboring tissues (Costet et al. 1999). Cell death observed upon multiplication of necrotrophic pathogens has a quite different nature and is driven, at least in part, by the secretion of toxins and lytic enzymes by the parasite (Oliver and Ipcho 2004), consistent with the virulence strategy of necrotrophs that derive energy from dead plant tissues. However, it was found that overexpression of homologs of the Bax inhibitor enhanced protection against Botrytis spp. infection, pointing to an active role of plant components in cell death 
triggered by necrotrophs (Imani et al. 2006). With the absence of homologs of caspase genes in plant genomes, the executionary phase of plant cell death has remained elusive for decades. Only recently was a tobacco enzyme called vacuolar processing enzyme (VPE) been shown to possess caspase-like activity and to be essential to virus-induced HR (Hatsugai et al. 2004). In Arabidopsis, proteolytic activity of VPE $\gamma$ regulates vacuolemediated collapse and has significant influence on mycotoxininduced cell death and pathogen resistance (Kuroyanagi et al. 2005; Rojo et al. 2004). Besides proteases, other lytic enzymes associated with plant cell death include nucleases (Dahiya 2003) or lipid acyl hydrolases (LAH).

Lipid metabolism has been recently found to play prominent roles in mounting resistance responses (Raffaele et al. 2008; Shah 2005). Particularly, lipid hydrolysis was reported in many pathosystems by the monitoring of enzymatic activity, lipid breakdown, or appearance of hydrolysis products. The functions of lipid hydrolysis are likely diverse, ranging from catabolic or energetic purposes to the synthesis of biologically active oxylipins. Oxylipins are oxidized FA derivatives that accumulate in free and bound forms in wounded and diseased plants but also play roles in development (Vellosillo et al. 2007). The oxylipins formed enzymatically through lipoxygenase (LOX) or $\alpha$-dioxygenase ( $\alpha$-DOX) pathways have been most studied (Feussner and Wasternack 2002; Hamberg et al. 2005; Howe and Schilmiller 2002; La Camera et al. 2004), but nonenzymatic generation is also active under oxidative stress (Thoma et al. 2004). In addition, large amounts of defined oxylipins esterified to galactolipids appear upon biotic challenge (Andersson et al. 2006) or wounding (Buseman et al. 2006) in Arabidopsis; however, the precise biosynthetic pathways and functions of these compounds are unclear. In contrast, three major functions have been assigned to free oxylipins: i) signaling of defense responses (Weber 2002), ii) direct antimicrobial properties (Prost et al. 2005), and iii) modulation of cell death (La Camera et al. 2004). This latter activity was inferred from the strong correlation between the accumulation of FA-hydroperoxides generated by the direct action of LOX and cell death symptoms in tobacco and Arabidopsis (Rusterucci et al. 1999; Vailleau et al. 2002). Conversely, 2-hydroxides produced by $\alpha$ DOX were proposed to protect tissues from excessive damage (De Leon et al. 2002; Hamberg et al. 2003) and help to limit the spread of the HR. The central role of jasmonic acid and its precursor 12-oxo phytodienoic acid (oPDA) and dinor-12-oxo phytodienoic acid (dinor-oPDA), collectively named here jasmonates (JA), in plant resistance appeared with the finding that mutants defective in either the biosynthesis of or responsiveness to JA displayed an enhanced susceptibility to necrotrophic pathogens or to insects. This effect is largely mediated by JA operating as master switches for the induction of arrays of downstream defense genes and metabolic pathways (La Camera et al. 2004; Wasternack 2007). Thus, it appears that oxylipins profoundly affect several aspects of pathogen defense.

Enzymes catalyzing the breakdown of acyl lipids and that could potentially affect the issue of plant-pathogen interactions were only poorly characterized. Genomic analysis has revealed multiple structural classes of LAH genes in the Arabidopsis genome (La Camera et al. 2004; Ryu 2004; Shah 2005). Sequence analysis suggests that these proteins interact with different cellular membrane systems to initiate appropriate responses. Only recently, specific functions and physiological implications of individual LAH were reported in defense or in development. The major structural plant LAH families include DEFECTIVE IN ANTHER DEHISCENCE 1 (DAD1)-like proteins (Ishiguro et al. 2001), PRLIP (Jakab et al. 2003), secreted $\mathrm{PLA}_{2}$ (Lee et al. 2005), GDSL-lipases/esterases (Oh et al. 2005), and patatin-like proteins (PLP) (La Camera et al.
2005). Most of these families have pathogen-inducible isoforms, pointing to the diversity of lipid hydrolysis events activated upon biotic stress. Members of the $\mathrm{SPLA}_{2}$ and the GDSL families, for example, have been described to display antifungal activity (Oh et al. 2005) or to promote susceptibility to bacteria (Hong et al. 2008), respectively. Also, the long-standing search for LAH initiating the biosynthesis of JA has identified the $D A D 1$ encoding a chloroplast-localized phospholipase $\mathrm{A}_{1}$ that triggers JA biosynthesis in flower buds (Ishiguro et al. 2001). DGL, a novel galactolipase of the DAD1-like protein $(D L P)$ family, behaves as the primary enzyme initiating wound-induced JA biosynthesis in leaves, but full biosynthesis also requires DAD1 (Hyun et al. 2008). In addition, the regulation of the lipolytic step for JA biosynthesis appears complex, because it also involves PLAI, an unusual LAH related to animal $\mathrm{iPLA}_{2}$, for maintaining resting levels of the hormone (Yang et al. 2007), and likely phospholipase D in early signaling (Bargmann and Munnik 2006; Hyun et al. 2008).

We previously investigated the patatin family of LAH that has nine members in Arabidopsis, including PLP2 and PLP7, which are pathogen responsive in leaves (La Camera et al. 2005). Of these two proteins, only PLP2 was enzymatically active on both galactolipids and phospholipids but inactive on triglycerols (Holk et al. 2002; La Camera et al. 2005). PLP2silenced plants exhibited enhanced resistance to Botrytis cinerea and to avirulent Pseudomonas syringae, whereas PLP2overexpressing plants were more susceptible to these pathogens, with more severe disease symptoms (La Camera et al. 2005). A positive correlation was also found between the level of PLP2 expression and paraquat-induced tissue damage. These observations suggested that PLP2 promotes host cell death. Here, we show that i) conversely, PLP2 contributes to resistance to Cucumber mosaic virus (CMV), an obligate pathogen; ii) some oxylipins accumulate in a PLP2-dependent manner in response to Botrytis spp. infection; iii) PLP2 promotion of cell death seems to attenuate expression of the JA-dependent marker $P D F 1.2$ and enhances stimulation of the salicylate (SA)-dependent marker PRI; and iv) PLP2 has a dramatic effect on the kinetics and severity of the spontaneous necrotic lesion phenotype in the vadl lesion mimic mutant. These data identify PLP2 as an important player in the execution of different forms of host cell death which, as a consequence, differentially impacts resistance to pathogens with distinct lifestyles.

\section{RESULTS}

\section{PLP2 contributes to resistance to a viral pathogen.}

The negative impact of $P L P 2$ overexpression on resistance to necrotrophic or hemibiotrophic pathogens and its cell-deathpromoting effects (La Camera et al. 2005) raised the question of the evolutionary gain that maintained this patatin gene in the Arabidopsis genome. Because the contribution of host cell death to resistance is variable for different types of pathogens (Glazebrook 2005), we hypothesized that the involvement of PLP2 in the generation of cell damage may be detrimental to the multiplication of an obligate parasite like a virus. This scenario was explored by investigating the impact of PLP2 misexpression on resistance to CMV. In Arabidopsis, only the C24 ecotype is known to react with an HR to the particular strain CMV(Y) (Takahashi et al. 1994), HR being determined by the single dominant RCY1 gene (Takahashi et al. 2002). All other tested ecotypes, including Col-0, are susceptible to the virus that spreads systemically to noninoculated parts of the plant. C24 and Col-0 plants were inoculated with CMV(Y) and displayed the expected phenotype (i.e., an absence of symptoms at 3 days postinoculation [dpi] in Col- 0 and discrete necrotic HR lesions dispersed on the leaf blade in C24) (Fig. 1A, top). 
Protein blot analysis showed that PLP2 was undetectable in inoculated Col-0 leaves while a clear signal was visible in $\mathrm{C} 24$ at 3 dpi (Fig. 1B, d3loc), indicating that PLP2 induction was associated with the CMV-triggered HR. At $7 \mathrm{dpi}$, systemic noninoculated leaves were symptomless in $\mathrm{C} 24$ while chlorotic (mosaic) symptoms appeared in Col-0 (Fig. 1A, middle). Neither of these two genotypes displayed systemic induction of PLP2 (Fig. 1B, d7 sys). Virus multiplication was quantified by RNA blot analysis using a probe derived from the $3^{\prime}$ untranslated region that is common to genomic and subgenomic RNAs 1, 2, 3, and 4 of the virus. At 3 dpi, the virus was detected in infected leaves of both wild-type ecotypes, at higher abundance in susceptible ecotype Col-0 (Fig 1C, d3 loc). The presence of viral RNA was analyzed in systemic, uninoculated leaves at $7 \mathrm{dpi}$. As expected, no virus was detected in C24, whereas a high level of viral RNA was observed in Col-0 (Fig. $1 \mathrm{C}, \mathrm{d} 7$ sys), consistent with the mosaic symptoms observed in these leaves (Fig. 1A, middle left). Col-0 PLP2-silenced, PLP2overexpressing, or Col-0 expressing an empty vector (as a control) were crossed with $\mathrm{C} 24$ and the progeny was analyzed for its response to CMV inoculation. Plants from the control cross displayed visible necrotic lesions, reflecting the dominant nature of $R C Y$-dependent $\mathrm{HR}$ in heterozygous plants. However, these lesions appeared slightly larger and with more diffuse margins than those of parental C24 plants (Fig. 1A, top). Western blotting confirmed the accumulation of PLP2 protein in control plants along with lesion formation while undetectable or strong constitutive levels were recorded in silenced and overexpressing plants, respectively (Fig. 1B, right). Symptom appearance was similar in the three genotypes and no quantifiable differences could be recorded. The virus was quantified and differential viral RNA accumulation was measured in the different lines: PLP2 silencing enhanced viral multiplication by approximately $40 \%$ while its overexpression reduced viral content by approximately $30 \%$ at $3 \mathrm{dpi}$. When these inoculated plants were incubated for longer times (up to $7 \mathrm{dpi}$ ), the youngest leaves, including the central meristem, started to turn chlorotic and developed necrosis along the midvein (Fig. 1A, bottom). This suggested that the HR triggered in these heterozygous plants was not fully efficient to restrict CMV to the inoculated leaves. These symptoms may reflect some systemic

Fig. 1. Analysis of the impact of patatin-like protein 2 (PLP2) deregulation on resistance to Cucumber mosaic virus (CMV). Adult leaves of 7-weekold plants were rubbed with a glass spatula dipped in a solution of purified CMV $(5 \mu \mathrm{g} / \mathrm{ml})$ containing carborundum and analyzed at various infection times. A, Symptoms of CMV infection: upper panel: 3-day-infected leaves of Col-0, C24 ecotypes, and the progeny of a Col- $0 \times$ C 24 cross. Middle and lower panels: systemic leaves of CMV-infected plants at 7 days postinoculation. White arrows indicate mosaic symptoms on Col-0 and inoculated leaves on C24 ecotypes. B, Accumulation of PLP2 protein in different genotypes after CMV inoculation. Leaves were harvested at the indicated times (numbers from 0 to 7 , in days) and protein extracts $(8 \mu \mathrm{g})$ were submitted to immunoblot analysis with PLP2-specific antibodies. Loc: inoculated leaves; Sys: systemic leaves. Full MW range of separation and recognition specificity of anti-PLP2 serum were described by $\mathrm{La}$ Camera and associates (2005). Equal protein loading was estimated by the intensity of large Rubisco subunit band after Coomassie staining of blots C, RNA blot analysis of CMV accumulation in PLP2-modified plants. Leaves were harvested at the indicated times (days). RNA was extracted, separated on formaldehyde gels, and transferred to a nylon membrane. Blots were hybridized successively with an actin 2 probe (Act) and with a probe specific for the $5^{\prime}$ untranslated region of RNAs 1, 2, 3, and 4 of CMV. Relative leaf content in CMV RNA was quantified as the sum of the signals of all four RNAs corrected with actin 2 signal. Amounts were normalized relative to the absolute value in control plants at day 3 that was set to 100 for each experiment. Data are mean and standard deviation of three independent, successive experiments. spread of the virus, resulting in trailing necrosis due to elicitation of the HR in the vascular system. Accordingly, PLP2 induction was found in systemic leaves of control plants that exhibited such symptoms (Fig. 1B, d7 sys Cont), and viral RNA accumulated in these tissues (Fig. 1C, d7sys Cont). As with inoculated leaves, PLP2 silencing generated higher viral titer in systemic leaves (approximately $170 \%$ of control), whereas PLP2 overexpression limited the viral content in these remote tissues (approximately $65 \%$ of control). Alternatively, transgenic C24 plants (obtained by direct transformation) that are silenced for or overexpress PLP2 were assayed for viral multiplication by real-time polymerase chain reaction (PCR). Again, inter-
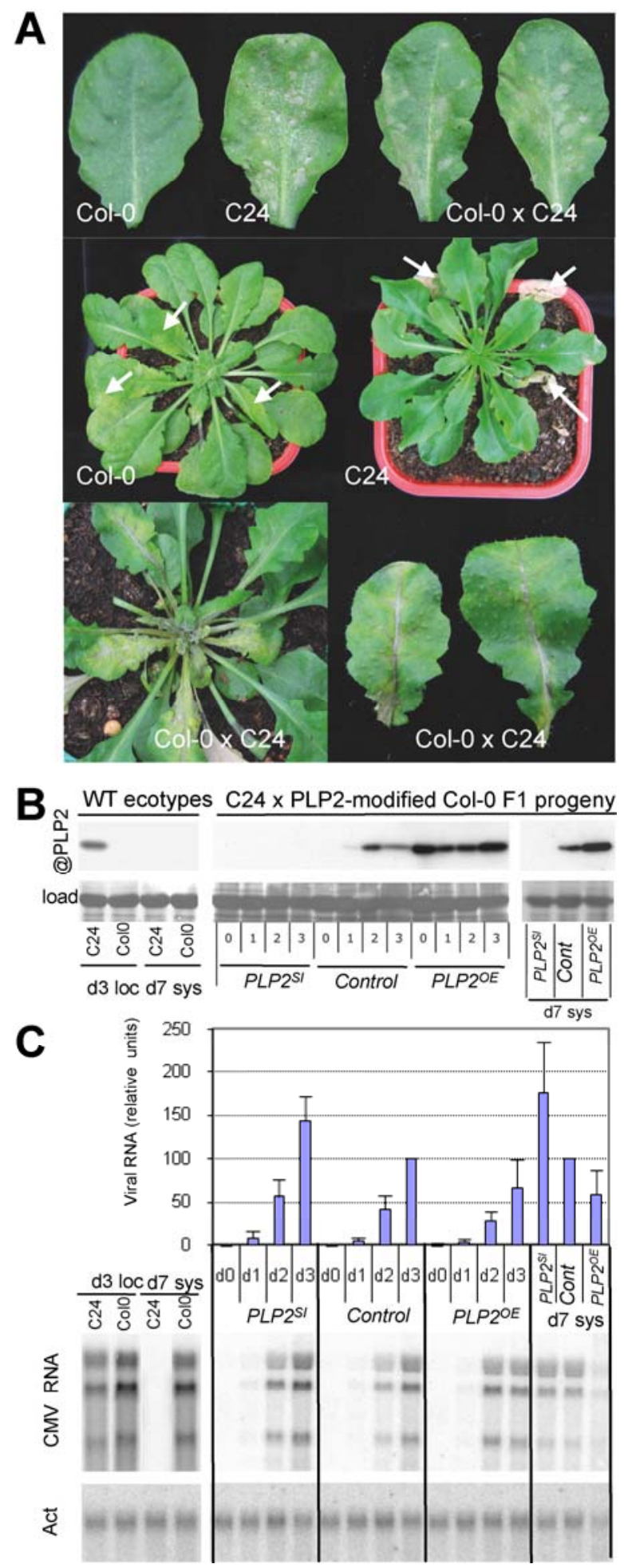

Vol. 22, No. 4, 2009 / 471 
fering with normal PLP2 induction resulted in differential CMV multiplication in inoculated leaves (Supplementary Fig. S1); however, in $\mathrm{C} 24$ background, no spread of CMV to systemic leaves was observed. Collectively, these results indicate that $P L P 2$ expression contributes to the plant resistance response to a viral pathogen upon HR-dependent process.

\section{Defense gene expression in response}

\section{to different pathogens is altered by PLP2 misregulation.}

Results presented in Figure 1 and our previous data (La Camera et al. 2005) establish that PLP2 misexpression has opposite impacts on resistance to viral, bacterial, and fungal pathogens (i.e., parasites differing both in their modes of plant colonization and in the responses they trigger). Such alterations in resistance may be consecutive of perturbed induction of defense responses. To evaluate this possibility, we monitored the accumulation of defense gene transcripts in the three pathosystems. The $B$. cinerea is known as a strong inducer of JA responses (AbuQamar et al. 2006) while $P$. syringae and CMV preferentially activate the SA pathway (Rairdan and Delaney 2002; Takahashi et al. 2002). As expected, PDF1.2 was best induced by $B$. cinerea (Fig. $2 \mathrm{~B}$ ) whereas $\mathrm{CMV}$ and $P$. syringae preferentially triggered high $P R l$ expression (Fig. 2C and E). Notably, under Botrytis attack, $P L P 2^{S I}$ plants expressed more $P D F 1.2$ than control plants, particularly at 2 dpi (Fig. 2B) whereas, conversely, $P L P 2^{O E}$ plants accumulated fewer $P D F 1.2$ transcripts. This fungus also markedly induced $P R I$, and for this gene, a further enhancement was seen in $P L P 2^{O E}$ plants (Fig. 2A). No reproducible effect of PLP2 misexpression on PRl expression in response to CMV was recorded (Fig. 2C) and the virus first caused a repression of PDF1.2 at 1 and $2 \mathrm{dpi}$, then a limited induction at 3 dpi (Fig. 2D). Interestingly, after infiltration of Pseudomonas bacteria, PRI induction was positively affected by PLP2 levels at later stages of infection, as seen from the antagonistic responses of $P L P 2^{S I}$ and $P L P 2^{O E}$ plants (Fig. 2E, 3 dpi). Finally, inoculation with this bacterial pathogen leads to a dramatic repression of $P D F 1.2$ (Fig. 2F), a finding that is consistent with public microarray data. This repression effect was not affected by PLP2 levels. In summary, PLP2 misexpression did not affect the preferential activation of the SA or JA pathways by different pathogens but positively or negatively modulated the amplitude of SA- or JAdependent defense markers in response to $B$. cinerea or $P$. syringae.

\section{PLP2 and oxylipin biosynthetic genes are highly induced upon Botrytis infection.}

PLP2 being an active lipid-deacylating enzyme (La Camera et al. 2005), it may affect cell death and pathogen resistance by providing fatty acid precursors for oxylipin biosynthesis. As a first step to test this hypothesis, we established kinetic expression profiles of a range of oxylipin biosynthetic genes representing various biosynthetic branches (Fig. 3) in leaves infected by either $B$. cinerea, $P$. syringae, or CMV. The genes analyzed were PLP2, the six Arabidopsis LOX isoforms, $\alpha-D O X$, and two genes from the JA pathway, namely, allene oxide synthase $(A O S)$ and OPDA reductase 3 (OPR3). The PRI and PDF1.2 transcripts were monitored as pathosystem markers. Arabidopsis has no divinyl ether synthase gene and, in the Col-0 ecotype, the hydroperoxide lyase (HPL) gene encodes a truncated, inactive protein (Duan et al. 2005). The genes under study showed a wide range of expression levels in control leaves that exceeded three orders of magnitude (Supplementary Fig. S2), with $L O X 1$ and $\alpha-D O X$ displaying the lowest basal expression. Most genes exhibited pathogen-specific profiles, differing both in timing and amplitude. PLP2 was induced by all three pathogens, but $B$. cinerea triggered the strongest response (Fig. 4). Among LOX, LOX1 showed the highest expression amplitude upon infection, while $L O X 5$ and $L O X 6$ were the less responsive. In terms of position specificity, LOX 1 and -5 were proposed as being 9-LOX, in contrast to LOX2, LOX3, LOX4, and LOX6, which are 13-LOX (Liavonchanka and Feussner 2006), suggesting the stimulation of both 9- and 13-LOX metabolisms. Although the three pathogens provoked expression changes, it appeared that $P L P 2, \alpha-D O X, L O X 2$, and $L O X 3$, as well as the genes involved in the synthesis (AOS and $O P R 3)$ or response to JA ( $P D F 1.2)$, were induced at the highest level by $B$. cinerea infection. In the case of $\alpha-D O X$, the stimulation factor reached
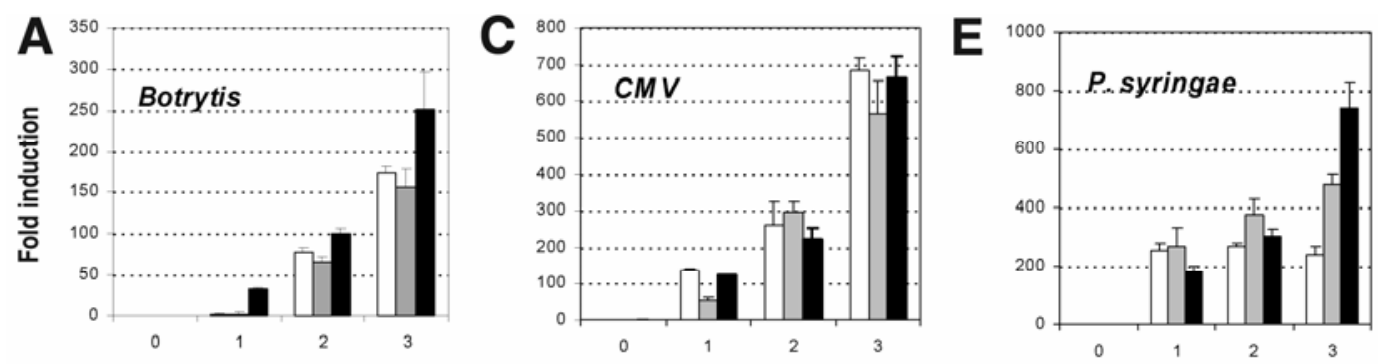

\section{PR1}
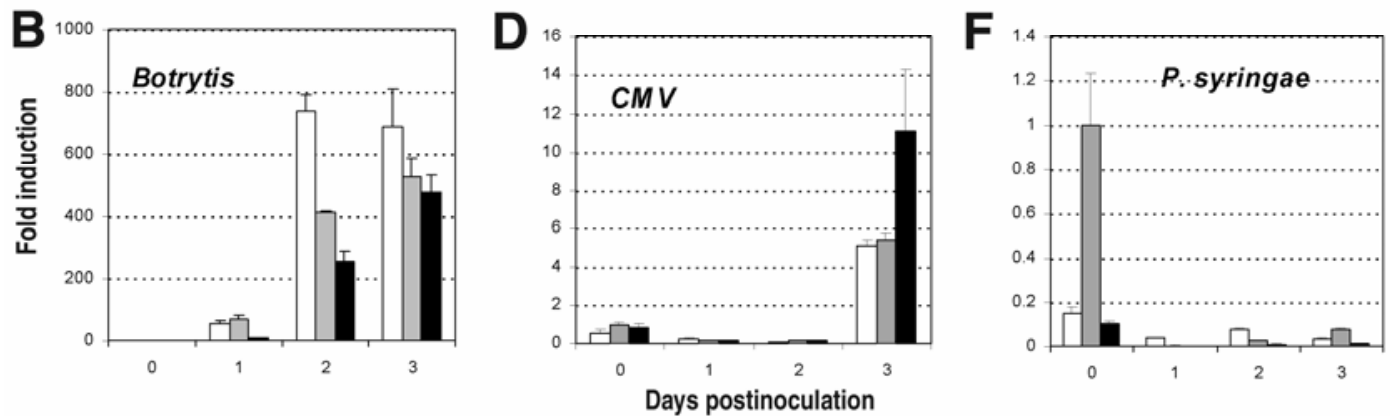

PDF1.2

Fig. 2. Effects of patatin-like protein 2 (PLP2) misexpression on defense gene induction. Quantification by real-time reverse-transcription polymerase chain reaction of the relative accumulation of PRI (top panels) and PDF1.2 (bottom panels) in the defense gene transcripts in $\mathbf{A}$ and $\mathbf{B}$, Botrytis spp. infection; $\mathbf{C}$ and $\mathbf{D}$, Cucumber mosaic virus (CMV) infection; and $\mathbf{E}$ and $\mathbf{F}$, Pseudomonas syringae pv. tomato avrRpm1 infection performed in PLP2-silenced (white bars), control (gray bars), or PLP2-overexpressing (black bars) plants. Actin 2 was used as a reference gene. For each gene-pathogen combination, data are expressed relative to the expression at day 0 in control plants. Each measurement is mean and standard deviation of three replicates and each experiment was repeated independently two to three times with similar results. 
25,000-fold. The PDF1.2 and PRI profiles were consistent with the described preferential activation of the JA or SA pathways by $B$. cinerea or $P$. syringae and $\mathrm{CMV}$, respectively. These expression data identified the $B$. cinerea as a potent inducer of many oxylipin biosynthetic genes, suggesting that other oxylipins in addition to JA may affect resistance to this fungus (Thomma et al. 1998). Therefore, we selected the Botrytis pathosystem to investigate the impact of PLP2 on oxylipin accumulation.

\section{PLP2 modulates the accumulation of oxylipins of the $\alpha$-DOX pathway in $B$. cinerea-infected leaves.}

The impact of PLP2 misregulation on resistance to $B$. cinerea and on the symptom severity (La Camera et al. 2005) could reflect changes in specific oxylipin pools. For example, because some oxylipins have been proposed to positively (Rusterucci et al. 1999; Vollenweider et al. 2000) or negatively (De Leon et al. 2002) affect plant cell death processes, feeding substrates into specific branches of oxylipin biosynthetic pathways would be a way to promote or to attenuate host cell damage. However, the ability of PLP2 to release fatty acids from both phospholipids and galactolipids in vitro along with its primary cytoplasmic localization (La Camera et al. 2005) did not indicate clearly which branch of oxylipin biosynthesis may be fed by PLP2. From gene expression data (Fig. 4), one can anticipate that a variety of oxygenated fatty acid derivatives accumulate in infected leaves. Approximately 25 compounds originating from pathways depicted in Figure 3 were separated and quantified from healthy and inoculated (at 1, 2, and 3 dpi) leaves from wild-type, silenced and overexpressing PLP2 lines. These included free fatty acids (FA) as direct products of LAH activity, FA hydro(pero)xides and keto FA as products of LOX activity, 2-hydroxy FA from the $\alpha$-DOX pathway, and cyclic oxylipins from the JA family (oPDA, JA, and dinor-oPDA). All compounds were undetectable or present at very low levels in unstimulated leaves and accumulated to variable levels after infection, illustrating the broad activation of oxylipin metabolism in response to $B$. cinerea attack. Free FA were the most abundant, with linoleic and $\alpha$-linolenic acid peaking at approximately 170 to $200 \mathrm{nmol}$ per gram of $\mathrm{FW}$ in control plants at 3 dpi (Fig. 5A, C18:2 and C18:3). PLP2 ${ }^{S I}$ plants showed a similar profile, whereas $P L P 2^{O E}$ plants had unchanged basal levels but displayed doubled levels of free C18:2 and C18:3 at 2 dpi compared with control plants. Hydroperoxy FA are the direct products of 9- or 13-LOX activity (Fig. 3) and are quite unstable in vitro. Under reducing conditions in the cytosol and the plastids, these compounds are converted to 9- or 13-hydroxy FA that are more stable and can be quantified (Feussner and Wasternack 2002). 9-HOD and 13-HOD on the one hand and 9-HOT and 13-HOT on the other hand, that derive from linoleic and $\alpha$-linolenic acid, respectively, accumulated to approximately 3 to $5 \mathrm{nmol}$ per gram of $\mathrm{FW}$ in control plants at 3 dpi (Fig. 5B). Their abundance was quite similar in $P L P 2^{S I}$ plants whereas, again, $P L P 2^{O E}$ plants exhibited a slightly increased accumulation of 9-HOD and 9-HOT at 3 dpi. High-performance liquid chromatography (HPLC) analysis showed the predominance (70 to $95 \%$ ) of the S-enantiomere in all cases (not shown), in accordance with an enzymatically catalyzed formation. Keto FA are products of a secondary peroxidase reaction of many LOX on hydroperoxy-FA (Feussner and Wasternack 2002) and were found to accumulate abundantly in B. cinereadiseased leaves, with 9-KOD and 9-KOT reaching 20 and 30 nmol per gram of FW, respectively (Fig. 5C). The build-up of these keto FA remained largely unchanged in $P L P 2^{S I}$ plants whereas, again, a moderate increase was recorded in $P L P 2^{O E}$ plants compared with controls (Fig. 5C). Then, we monitored the accumulation of the JA oPDA, JA, and dinor-oPDA. As previously reported, oPDA was by far the most abundant jasmonate, ranging from $1 \mathrm{nmol} / \mathrm{g}$ in unchallenged leaves to several hundred nanomole per gram of $\mathrm{FW}$ at $3 \mathrm{dpi}$ in control plants (Fig. 5D). JA levels were much lower and culminated at 15 to $20 \mathrm{nmol}$ per gram of $\mathrm{FW}$ at $3 \mathrm{dpi}$ while dinor-oPDA amounts were found at intermediate levels (45 nmol per gram of FW). The levels of all three jasmonates were slightly reduced or increased by PLP2 depletion or overexpression, respectively.

In addition to the formation of LOX-derived compounds, $\alpha$ DOX, a distinct pathogen-induced oxygenase, generated a series of 2-hydroxy FA (Fig. 3) (Hamberg et al. 2003) that were suggested to protect plant tissues from excessive cell death. 2-OH FA were induced to variable levels in our experiments and, interestingly, a differential accumulation was apparent in PLP2modified plants, essentially at $3 \mathrm{dpi}$. For example, the most abundant compound, 2-OH-C16:0 (2-HHA), was reduced almost threefold in $P L P 2^{S I}$ plants compared with controls, while these levels in $P L P 2^{O E}$ were doubled (Fig. 5E). A similarly reduced accumulation in silenced plants was recorded for the

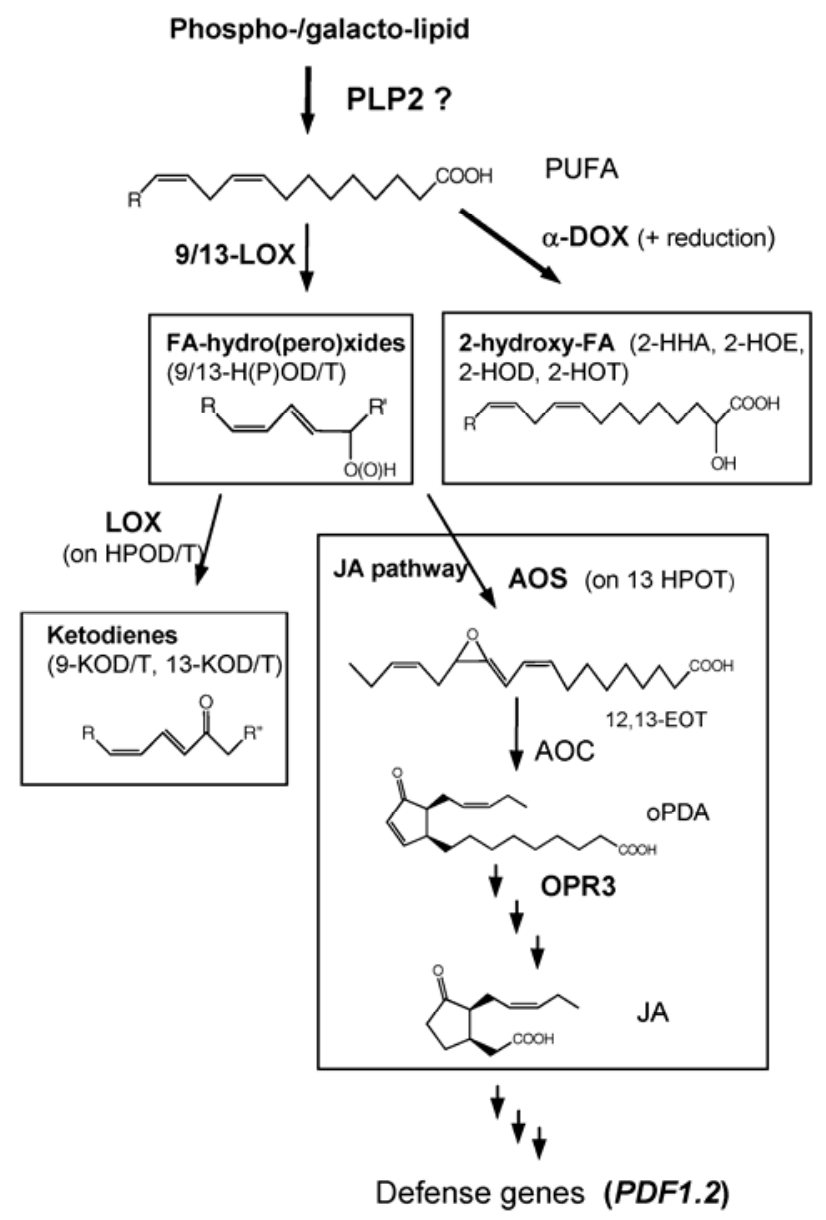

Fig. 3. Simplified view of enzymatic pathways leading to defense-related oxylipin biosynthesis in Col-0 Arabidopsis. The putative position of patatin-like protein 2 (PLP2) upstream of oxylipin pathways is shown. $\alpha$ DOX: a-dioxygenase; AOS: allene oxide synthase; AOC: allene oxide cyclase; LOX: lipoxygenase; OPR3: 12-oxo phytodienoic acid reductase 3; PUFA: polyunsaturated fatty acid. Major compounds issued from each biosynthetic branch are listed by their abbreviated names. FA: fatty acid; 9- or 13-H(P)O(D/T)E: 9- or 13-hydro(pero)xy octadeca(di/tri)enoic acid; 9- or 13-KO(D/T)E: 9- or 13-keto octadeca(di/tri)enoic acid; 2-HHA: 2hydroxy hexadecanoic acid or 2-OH C16:0; 2-HOA: 2-hydroxy octadecanoic acid or 2-OH-C18:0; 2-HOE: 2-hydroxy octadecanoic acid or 2-OHC18:1; 2-HOD: 2-hydroxy octadecadienoic acid or 2-OH-C18:2; 2-HOT: 2-hydroxy octadecatrienoic acid or 2-OH-C18:3; 12,13-EOT: $(12,13 S)$ epoxy octadecatrienoic acid; OPDA: 12-oxo phytodienoic acid; JA: jasmonic acid. 
less abundant compounds 2-OH-C18:0 (2-HOA) and 2-OHC18:1 (2-HOE) (Fig. 5F). To further investigate the effect on this class of oxylipins, two independent determinations of five species of 2-OH FA were performed. Although a different overall magnitude of the response was observed in this experiment, four of five compounds (2-OH-C16:0, 2-OH-C18:1, 2$\mathrm{OH}-\mathrm{C} 18: 2$, and 2-OH-C18:3) showed a clear antagonistic, PLP2-dependent accumulation, again mostly at 3 dpi (Supplementary Fig. S3).

In summary, these data illustrate the induced accumulation of a wide array of 9- and 13-oxylipins in response to $B$. cinerea attack and reveal that PLP2 expression promotes accumulation of $\alpha$-DOX derivatives at later stages but has only a minor impact on other oxylipins.

\section{PLP2 misexpression modifies cell death timing and severity} in a lesion mimic mutant.

Interfering with $P L P 2$ expression had significant impacts on the accumulation of some oxylipins and on resistance or defense to different pathogens; therefore, its possible involvement in cell death regulation or execution, a key process regulating all these events, was investigated. This hypothesis was genetically tested using a cell death mutant. The vadl mutant displays spontaneous necrotic HR-like lesions upon development, with lesions propagating along the vascular system, and shows associated upregulation of defense signaling pathways and downstream responses (Lorrain et al. 2004). The use of such a model system allows examining the contribution of PLP2 to plant cell death independently of pathogen-specific factors. A timecourse experiment was performed to analyze PLP2 expression by Western blotting in vadl grown under lesion-promoting conditions (Fig. 6A). Under such conditions, lesions appear typically at day 21 after transplanting. PLP2 was undetectable at early stages when leaves were symptomless and accumulated at the onset of necrotic lesion appearance (Fig. 6A). In order to address the influence of PLP2 expression on the cell death process, lines misexpressing $P L P 2$ were crossed with the vadl mutant. Parental $P L P 2^{O E}$ plants never displayed any necrotic symptoms in absence of infection, as revealed by trypan blue staining (not shown). Homozygous double-mutant plants were selected by PCR in the F2 population. Because vadl is in Ws background and PLP2-modified lines in Col-0, a cross of vadl with a line containing the empty vector in Col-0 background was performed as a control. The F2 progeny of this cross exhibited kinetics of appearance and intensity of lesions similar to the parental Ws vadl (not shown). The vadl, $v a d 1 / P L P 2^{S I}$, and vad1/PLP2 ${ }^{O E}$ plants were grown under lesionpromoting conditions, and occurrence of cell death symptoms was recorded over a period of 2 weeks starting from day 15 to day 29 after transplanting. Leaf samples were harvested at the same times for protein analysis. vad1/PLP2 $2^{S I}$ and vad1/PLP2 $2^{O E}$ plants exhibited undetectable and high-constitutive PLP2 expression, respectively (Fig. 6A), as did the $P L P 2^{S I}$ and $P L P 2^{O E}$ parents. The vadl plants displayed the first necrotic leaves be-
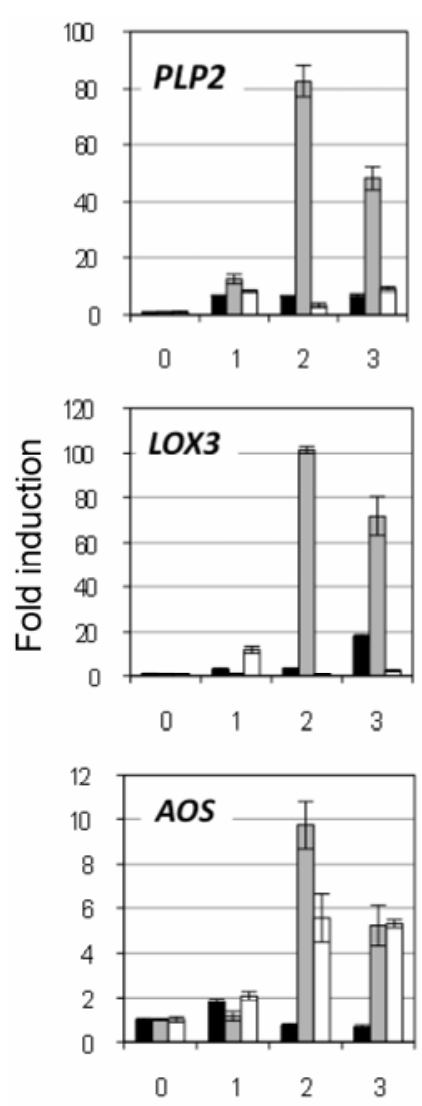

CMV
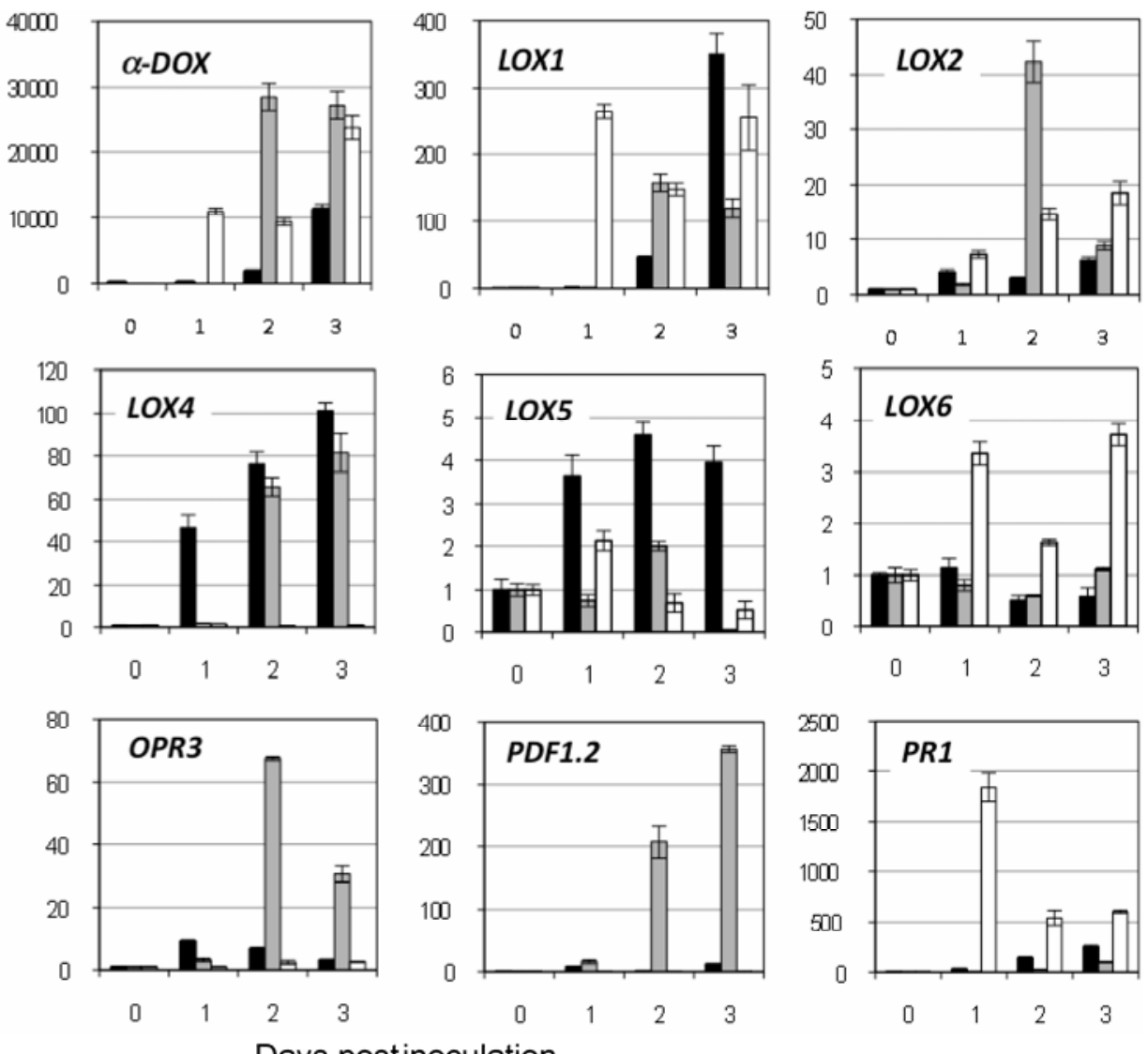

Days postinoculation

\section{$\square$ B. cinerea}

\section{P. syringae}

Fig. 4. Expression dynamics of patatin-like protein 2 (PLP2), oxylipin biosynthetic genes, and defense markers PDF1.2 and PR1 in Arabidopsis plants infected by either Botrytis cinerea (gray bars), Pseudomonas syringae (white bars), or Cucumber mosaic virus (CMV) (black bars). Leaves have been harvested at the indicated times (days) after inoculation. RNA was extracted, reverse transcribed, and subjected to real-time polymerase chain reaction using gene-specific primers. Data were normalized with actin 2 as reference gene and displayed relative to expression at day 0. Each measurement is the mean and standard deviation from three replicates and similar results were obtained from two independent experiments. 
tween day 19 and 21. At days 26 and 29, more than 50\% of leaves exhibited necrotic areas that extended to most of the leaf blade at day 29 (Fig. 6B and C). vad1/PLP2 ${ }^{S I}$ showed a significant reduction in the number and severity of lesions. No leaf damage was visible before day 26 , when less than $10 \%$ of leaves were necrotic. By day 29, this proportion barely reached $20 \%$, resulting in very mild symptoms even at the end of the period under study (Fig. 6B and C). In sharp contrast, vad1/PLP2 ${ }^{O B}$ exhibited a dramatic enhancement of the number and intensity of necrotic symptoms, manifested on adult leaves. In populations overexpressing $P L P 2$, only the younger leaves were devoid of massive tissue collapse. vad1/PLP2 $2^{O B}$ plants showed approximately $50 \%$ necrotic leaves as early as day 15 after transplanting and at least $70 \%$ of leaves suffered severe tissue damage between day 21 and 29 after transplanting (Fig. 6B and C). These observations indicate that the level of expression of PLP2 has a profound impact on the extent of cell death occurring in a spontaneous lesion-mimic mutant. To investigate how these phenotypic changes affect defense gene induction that was described for vadl upon lesion appearance (Lorrain et al. 2004), we examined the expression profiles of PRI and PDF1-2 defense markers under lesion-promoting con-
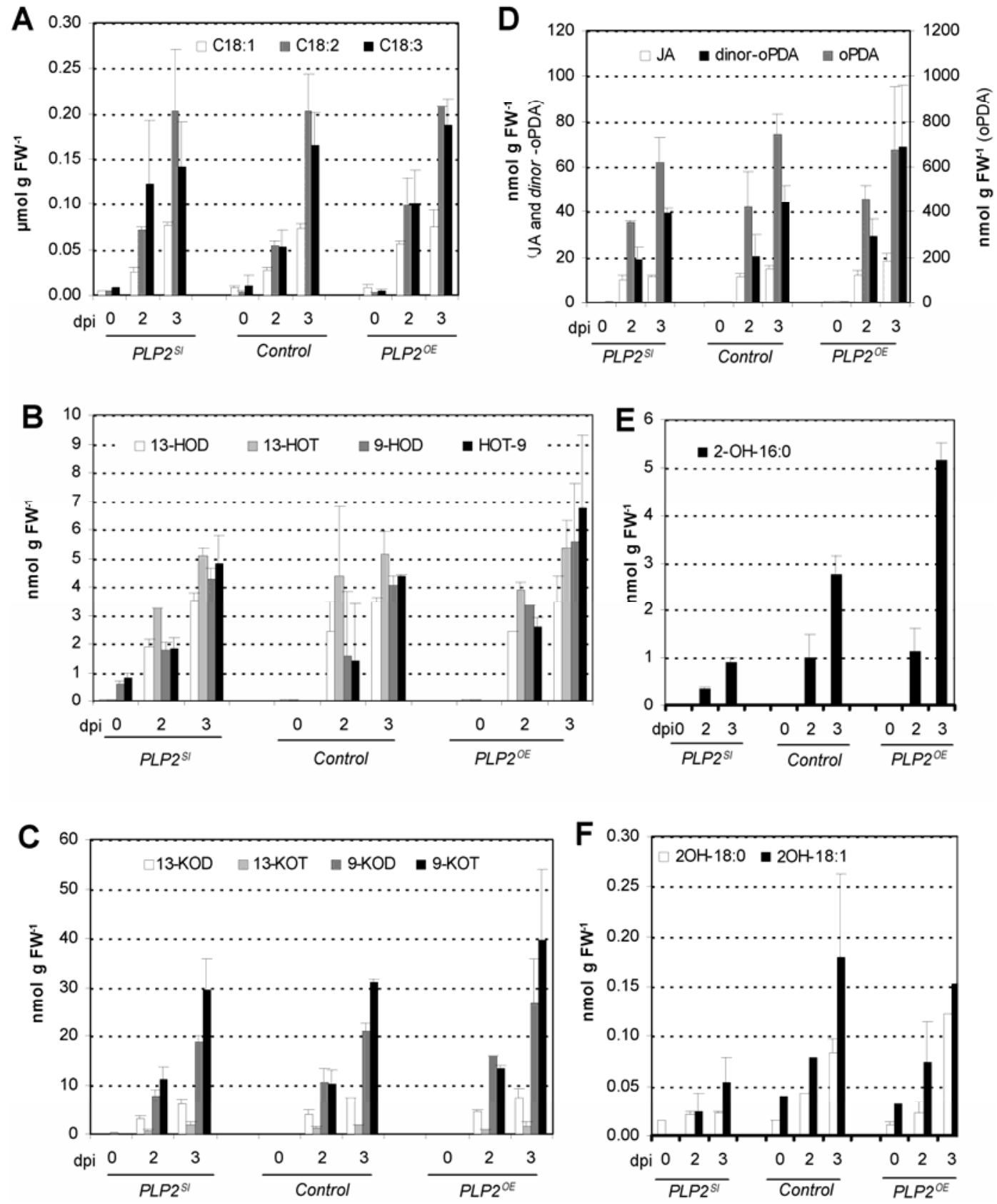

Fig. 5. Time course accumulation of free fatty acids and oxylipins upon Botrytis spp. infection in patatin-like protein 2 (PLP2)-deregulated plants. A, Free fatty acids (FAs); B, 9- and 13-hydroxy-FAs; C, keto-FAs; D, jasmonates; $\mathbf{E}$ and $\mathbf{F}, 2$-hydroxy-FAs. Leaf samples were harvested at 0 , 1, 2, and 3 days postinoculation. For clarity, the day 1 data are not illustrated because, in most of the cases, they were very similar to those of untreated leaves. Note that $y$ scales vary between graphs. A specific scale is used for 12-oxo phytodienoic acid (oPDA) on the right axis of graph D. FA: fatty acid; 9- or 13-H(P)O(D/T)E: 9- or 13-hydro(pero)xy octadeca(di/tri)enoic acid; 9- or 13-KO(D/T)E: 9- or 13-keto octadeca(di/tri)enoic acid; 2-HHA: 2-hydroxy hexadecanoic acid or 2OH C16:0; 2-HOA: 2-hydroxy octadecanoic acid or 2-OH-C18:0; 2-HOE: 2-hydroxy octadecanoic acid or 2-OH-C18:1; 2-HOD: 2-hydroxy octadecadienoic acid or 2-OH-C18:2; 2-HOT: 2-hydroxy octadecatrienoic acid or 2-OH-C18:3; 12,13-EOT: (12,13S)-epoxy octadecatrienoic acid; dpi: days postinoculation. Data represent duplicate biological samples with deviation of an experiment representative of three biological replicates with similar trends between genotypes. 

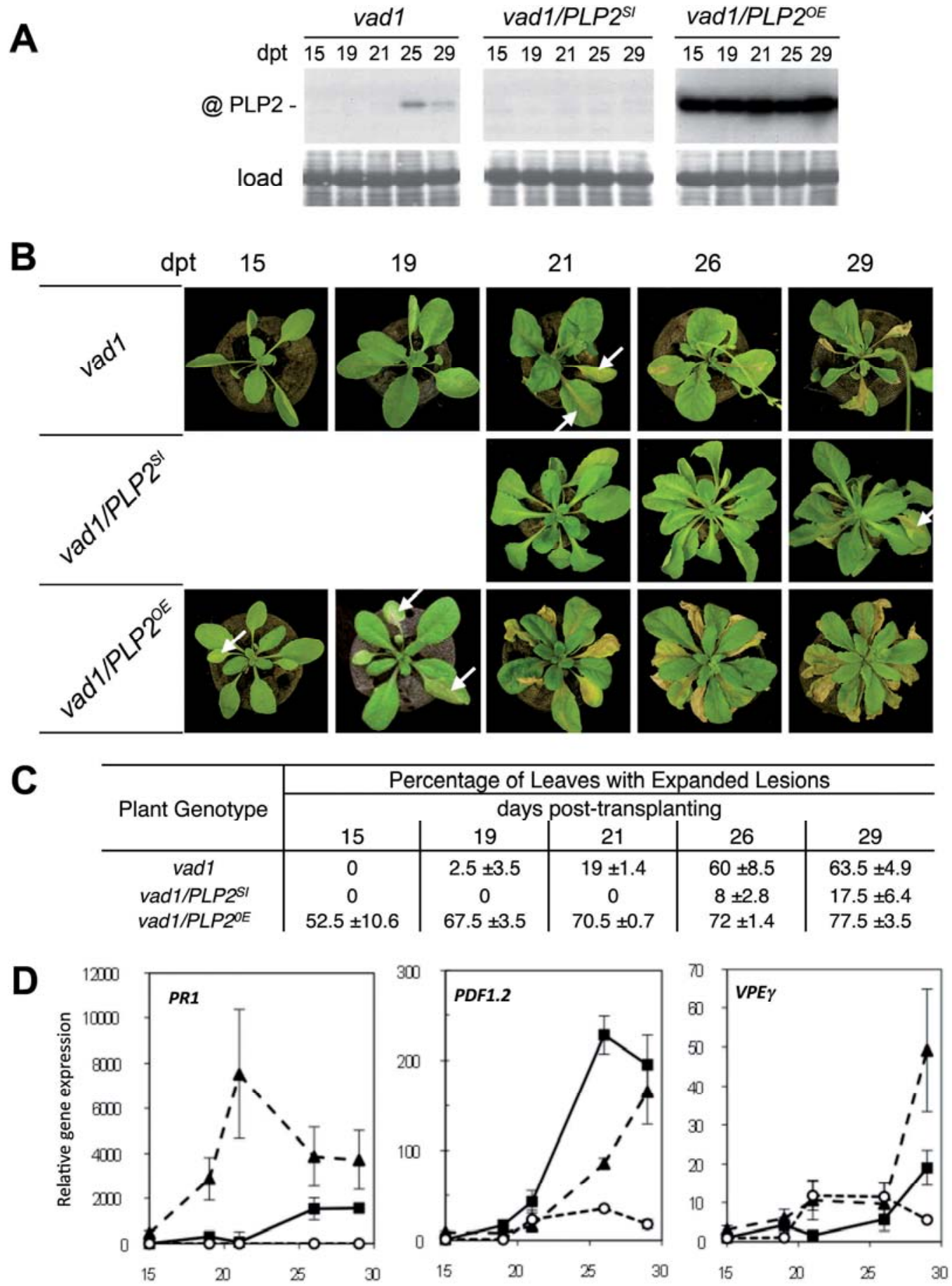

Days post-transplanting

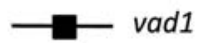

$--\mathrm{O}-\cdots \cdot \operatorname{vad1/PLP2} 2^{S I}$

$-\mathbf{-} \cdot \operatorname{vad} 1 / P L P 2^{O E}$

Fig. 6. Patatin-like protein 2 (PLP2) expression and impact of its deregulation on cell death and defense phenotypes in the vascular-associated death 1 (vad1) background. A, Time course protein blot analysis of PLP2 expression in vad1 plants and vad1 plants expressing PLP2-silencing or overexpression constructs. Plants were grown for 5 to 6 weeks under lesion-promoting conditions and fully expanded leaves were harvested on various days after transplanting $(\mathrm{dpt})$ as indicated. Protein extracts $(8 \mu \mathrm{g})$ were submitted to immunoblot analysis with a PLP2-specific antibody. Equal loading was estimated by the intensity of large Rubisco subunit band after Coomassie staining of blots (load). B, Time course study of spontaneous cell death symptom appearance in vad1 mutant plants or in vad1 plants silenced for or overexpressing PLP2. Plants were photographed at indicated dpt. Arrows indicate first leaves presenting cell death symptoms for each genotype. C, Scoring of cell death phenotypes visualized in B. Numbers represent percentage of leaves with lesions in vad1 and in vad1/PLP2-modified plants. Mean and standard deviation are from two F2 double-mutant populations originating from independent crosses (50 plants per population for each $v a d 1 / P L P 2$ genotype). The experiment was repeated three times with similar results. D, Relative transcript levels of defense and cell death marker genes. $P R 1, P D F 1.2$, and $V P E \gamma$ transcripts were quantified by real-time reverse-transcription polymerase chain reaction in RNA extracted from samples harvested at increasing times after transplantation. Closed squares: vad1; open circles: vad1/PLP2 ${ }^{S I}$; closed triangles: vad1/PLP2 ${ }^{O E}$. Data are expressed relative to signal at day 15 in vadl as means and standard deviation of two biological replicates. 
ditions, along with $V P E \gamma$, a recently described cell death effector (Hatsugai et al. 2004). These three genes were induced to different extents in vadl, as expected (Fig. 6D). Overexpression of PLP2 in vadl resulted in a dramatic or moderate enhancement in $P R I$ or $V P E \gamma$ induction, respectively, and the $P D F 1.2$ response was lower than in vadl. In vadl/PLP2 $2^{S I}$ lines, upregulation of the defense markers $P R I$ and $P D F 1.2$ was considerably reduced (nearly abolished for $P R I$ ), whereas the induction of $V P E \gamma$ was maintained but occurred earlier than in vadl. These results suggest that late defense gene expression in vadl is largely dependent on cell death execution controlled by PLP2. In contrast, $V P E \gamma$ induction seems to be triggered independently of PLP2 levels but is not sufficient to bring about cell death in the absence of PLP2.

\section{DISCUSSION}

A role of inducible leaf patatins in defense was initially suggested in tobacco undergoing pathogen- or elicitor-triggered cell death (Dhondt et al. 2000, 2002). The goal of the present work was to define the contrasted impacts of PLP2, the only inducible patatin exhibiting LAH activity in Arabidopsis, on distinct pathosystems. We studied its role in resistance to an obligate pathogen and its relationship with fungus-induced oxylipin biosynthesis in plant lines misexpressing PLP2. The involvement of PLP2 in programmed cell death was also genetically tested using a cell death mutant, vadl, and our findings demonstrated its prominent role in cell death execution.

\section{The role of PLP2 in resistance depends on the pathogen lifestyle.}

Our previous data identified a negative impact of PLP2 expression on resistance to the necrotrophic Botrytis and to the hemibiotrophic Pseudomonas pathogens, in both cases through the exaggeration or perturbation of distinct forms of host cell death (La Camera et al. 2005). We tested the plant lines misexpressing PLP2 for their behavior after inoculation of the true biotrophic oomycete Hyaloperonospora parasitica (B. MauchMani, unpublished) or the fungus Erysiphe orontii (C. Denoux, unpublished) but in neither case was the resistance to virulent or avirulent strains altered compared with control plants. In support to these observations, these pathogens are poor inducers of $P L P 2$ expression and they trigger resistance pathways that do not involve massive host cell death.

It is generally assumed that the programmed cell death associated with the HR contributes to resistance against viruses, because obligate parasites are dependent on living tissues to replicate in their hosts (Hatsugai et al. 2004). To examine the influence of PLP2 on HR-mediated resistance against a virus, we generated PLP2-deregulated plants that react to CMV with an HR by crossing modified Col-0 lines with the naturally resistant C24 ecotype. The F1 progeny reacted with a localized $\mathrm{HR}$, and CMV resistance analysis, estimated by the quantification of viral RNA, revealed here a positive correlation between PLP2 expression and antiviral resistance. This effect was observed in both inoculated and systemic leaves which exhibited trailing necrosis around midveins of younger leaves. Such symptoms, indicating that some virus escaped the inoculated leaves, suggested that full restriction of CMV to inoculated sites was gene dosage dependent. Alternatively, C24 transgenic plants silenced for or overexpressing PLP2 exhibited the same phenotypes for local resistance. Furthermore, the overexpression of NtPAT3, a tobacco pathogen-induced patatin, resulted in enhanced resistance to Tobacco mosaic virus (G. Gouzerh and T. Heitz, unpublished). Unexpectedly, despite differential resistance phenotypes between Arabidopsis genotypes (both in Col-0 $\times$ C24 hybrids and in C24), we did not observe macro- scopic differences in HR severity in inoculated leaves. This result could reflect antagonistic effects exerted on cell death; milder HR due to the absence of PLP2 may result in the subsequent increased CMV spread which can, in turn, elicit more HR in surrounding tissue compared with controls. Conversely, enhanced ability to execute cell death in $P L P 2^{O E}$ plants may not be apparent in terms of lesion size because it prevents more efficiently radial spread of the virus and, consequently, of the lesions. Importantly, these data identify PLP2 as a positive effector of antiviral resistance and illustrate that the outcome of PLP2 expression can be beneficial or detrimental to the plant depending on the type of biotic attack encountered.

\section{Oxylipins and their role in PLP2 conferred phenotypes.}

To try to understand the biochemical basis of PLP2-related phenotypes, we hypothesized that they may be linked to its ability to degrade membrane lipids, releasing FA that could, in turn, feed the formation of bioactive oxylipins. To guide the choice of the pathosystem for detailed oxylipin profiling, we first compared the transcriptional response of $P L P 2$ and major oxylipin biosynthetic genes with CMV, Botrytis, or Pseudomonas infections. Although some of these genes had been reported individually for their response to environmental stress (particularly herbivores), the kinetic details of their reactivity to unrelated microbes had not been reported. PLP2 expression correlated well with the induction of proven oxylipin genes such as $\alpha-D O X$ and several LOX, $A O S$, and $O P R 3$. Among LOX, $L O X 1$ to $L O X 4$ were the most pathogen responsive (taking into account variable basal levels), with $L O X 2$ having the highest absolute expression level. All three pathogens induced many of the genes, with pathogen-specific profiles, suggesting that each attacker likely triggers a specific oxylipin signature. Importantly, $B$. cinerea appeared to be the strongest inducer of the largest number of genes, justifying this pathosystem as the preferred model for the determination of oxidized FA metabolites.

We first analyzed free FA levels as direct products of LAH activity. All C18 FA displayed an increased accumulation in response to infection, with linole(n)ic acids being the most abundant ones. Surprisingly, silencing of PLP2 did not significantly modify this profile, suggesting that LAH other than PLP2 contribute in addition to the build-up of free FA pools. Concerning oxylipins, most studies have focused on the activation of JA signaling for defense or resistance (Laurie-Berry et al. 2006; Staswick et al. 1998; Thomma et al. 1998; Vijayan et al. 1998), and a global spectrum of oxylipins appearing upon pathogenesis has only been explored in a few cases (Göbel et al. 2002, 2003). The diverse biological activities borne by different oxylipin classes make it important to determine global oxylipin signatures to consider all compounds that may influence the outcome of infections. For example, the cell-deathpromoting effects of PLP2, inferred from symptom scoring, prompted us to profile compounds that have been shown to modulate cell or tissue damage. Cell-death-promoting oxylipins belong to a group of chemically reactive compounds that derive directly from LOX-generated FA hydro(pero)xides (Rusterucci et al. 1999) or FA ketodienes (Vollenweider et al. 2000). Enzymatic lipid peroxidation has been proposed to be a biochemical marker of HR cell death in plants (Montillet et al. 2002). These authors also provided correlative evidence suggesting that the combined action of 9-LOX and patatin-borne galactolipase is sufficient to cause hypersensitive cell death in tobacco (Cacas et al. 2005). In parallel, $\alpha$-DOX produces 2hydroperoxy FA in vitro but its major output in infected tobacco leaves was found to be the reduced form 2-hydroxylinolenic acid (2-HOT) (Hamberg et al. 2003). 2-HOT was described as protecting tobacco leaves from HR collapse when co-infiltrated with $P$. syringae bacteria. This and previous genetic evi- 
dence in Arabidopsis supported a model where $\alpha$-DOX generates FA derivatives that protect plant tissues from excessive cell death (De Leon et al. 2002). In this work, we established the strong activation of several branches of oxylipin biosynthetic pathways in $B$. cinerea-infected leaves. The identified compounds originated from 9-LOX, 13-LOX, and $\alpha$-DOX activities, in agreement with gene expression data. Unexpectedly, we could not confirm genetically a clear PLP2 dependence for the accumulation of known cell-death-promoting oxylipins. Profiling showed a similar accumulation of 9- and 13-LOX-derived FA hydro(pero)xides in control plants but a more abundant presence of 9- over 13-LOX-derived FA ketodienes. Lipoxygenases have been categorized into plastid and nonplastid isoforms (Feussner and Wasternack 2002) and, thus, several pools of FA hydro(pero)xides and possibly ketodienes are likely generated from distinct pools of precursor FA. Most LOX-derived compounds showed little or no changes in accumulation dynamics in PLP2-deficient plants versus controls, while levels were generally increased in $P L P 2^{O E}$ plants. Such an effect of PLP2 overexpression may be indirect and related to the larger lesion sizes, implying a larger area of stimulated tissue in these latter plants. The JA also followed this trend and, therefore, differential induction of PDF1.2 shown in Figure 2 is likely due to changes in downstream JA signaling rather than in biosynthesis of the JA signal. By contrast, the abundance of $\alpha$-DOX derivatives was antagonistically affected by $P L P 2$ silencing or overexpression, providing evidence that PLP2 at least partly provides precursor FA for this pathway. Such an interpretation apparently contradicts the proposed cell-death-protecting properties of 2-hydroxy FA produced by $\alpha$-DOX (De Leon et al. 2002). These properties were inferred from experiments with $P$. syringae-infected or paraquattreated plants, but the impact of $\alpha$-DOX derivatives on $B$. cinerea-triggered cell death were not described. Also, the interactions and outputs of pro- and anti-cell-death oxylipin pathways need to be further studied. Finally, diseased tissues produce abundant lipid-bound phytoprostanes with defensive roles (Thoma et al. 2004) that were not investigated here and that may be mobilized by PLP2.

\section{PLP2 affects the balance \\ between cell death and defense signaling.}

It is generally assumed that dying cells are a source of secondary signals orchestrating the intense upregulation of defense responses in neighboring living tissues (Costet et al. 1999; Greenberg and Yao 2004). The altered levels of pathogen multiplication could be the result of a perturbation of signaling leading to defense gene induction. Interestingly, we found such alterations in defense marker gene induction. The $B$. cinerea response of the JA marker $P D F 1.2$ was negatively affected by PLP2 expression. In contrast, the levels of the SA marker PRI were positively correlated with the abundance of PLP2 in response to $P$. syringae but, surprisingly, also after $B$. cinerea attack. These observations reveal that PLP2 differentially modulates the amplitude of two highly induced defense genes in two unrelated pathosystems, and may reflect a differential sensitivity of JA and SA signaling to the intensity of cell death. The attenuation of cell death observed in $P L P 2^{S I}$ plants ( $\mathrm{La}$ Camera et al. 2005) may result in an increase in the JA signaling capacity of the tissues, whereas the accelerated collapse of $P L P 2^{O E}$-infected tissues reduces the time frame for active JA signaling. In such a scenario, $B$. cinerea would benefit from inducing rapid cell death in order to minimize JA responses. In contrast, enhanced SA signaling in response to $P$. syringae seems to result from higher capacity to undergo cell death. This is in accordance with the positive functional link between cell death and the SA pathway that was described in other sys- tems (Dong 2004; Raffaele et al. 2006). Differential sensitivity of $P D F 1.2$ and $P R 1$ to cell death intensity was also apparent in the vadl mutant (Fig. 6D), in which PRI levels were positively correlated with tissue damage while perturbing cell death kinetics or intensity decreased PDF 1.2 levels. These findings illustrate that a tight control of the cell death process is critical for the regulation of defense mechanisms, in order to optimize the benefits of both localized cell death and induction of defenses.

\section{PLP2 as an executioner of various types of cell death.}

Although the involvement of oxylipins in mediating phenotypic effects of PLP2 misregulation appeared more subtle than anticipated, we investigated whether the genetically triggered form of spontaneous cell death occurring in the vadl mutant was affected by PLP2. VADl encodes a gram-domain membrane protein and its loss of function results in the light-dependent appearance of propagative HR-like lesions along the vascular system. This phenotype is dependent on salicylic acid (Lorrain et al. 2004) and ethylene (Bouchez et al. 2007) pathways and is correlated with the upregulation of multiple defense responses. Accordingly, vadl exhibits increased resistance to $P$. syringae pv. tomato infection. The upregulation of PLP2 expression at the onset of lesion appearance in vadl suggested its possible involvement in the control of spontaneous cell death; thus, this mutant provided a valuable tool to test this hypothesis in the absence of any toxic effector derived from a pathogen. We demonstrated that deregulation of PLP2 expression dramatically changed the dynamics of the vadl cell death phenotype. In $P L P 2^{S I}$ plants, intensity of the vadl-conferred cell death phenotype was considerably diminished. This clearly demonstrates that full deployment of HR-like lesions requires PLP2 expression. Conversely, PLP2 overexpression in a vadl background results in an acceleration and amplification of leaf damage. What could then be the mode of action of PLP2 to promote cell death? The fact that PLP2 overexpression does not yield any visible phenotype or constitutive decrease in polar lipid content in the absence of stress (P. Geoffroy and T. Heitz, unpublished) indicates that the enzyme does not function as an initial switch committing tissues to engage in a death program but, more likely, catalyzes lipid hydrolysis only when a threshold of stress signaling or cellular unbalance has been reached. More precisely, we have shown that PLP2 is upregulated by all necrotizing stimuli examined, covering attacks by a wide range of microbes (La Camera et al. 2005; this study) and lesion appearance in a cell death mutant. In this latter model system, its misexpression had particularly spectacular consequences. The rather wide lipid substrate range (La Camera et al. 2005) and long-lasting induced expression of PLP2 argue in favor of its involvement at later phases to catalyze an extensive hydrolysis of membrane lipids. This would lead to the disruption of membrane functions that is a critical event in cell death execution (Greenberg and Yao 2004). Therefore, we propose that PLP2 functions as a common executioner of plant cell death programs triggered by unrelated biotic attackers or genetic lesions. Interestingly, whereas the induction of downstream PRI and PDF1.2 defense markers was abolished or diminished, respectively, in vadl/PLP2 $2^{S I}$ plants compared with $v a d l$, the induction of the $V P E \gamma$ protease gene was maintained despite the near absence of symptoms. This suggests that $V P E \gamma$ regulation is upstream or independent of PLP2, and that efficient execution of cell death in leaves requires both VPE $\gamma$ and PLP2. It is possible that membrane lipid hydrolysis at unknown sites cooperates with the release of other lytic enzymes from vacuoles by VPE $\gamma$ (Hatsugai et al. 2004). While such decompartmentalization occurs, a subset of FA released by PLP2 would be converted to specific oxylipins by newly 
stimulated pathways to reinforce the antimicrobial arsenal of dying cells. Determining the subcellular details of PLP2 action and of such a cooperation clearly deserves new lines of investigation.

\section{MATERIALS AND METHODS}

\section{Biological material.}

Arabidopsis plants were grown under controlled conditions in a growth chamber under a regime of 20 and $16^{\circ} \mathrm{C}$, day and night, respectively, with a 12 -h photoperiod at $70 \mu \mathrm{mol} \mathrm{m} \mathrm{m}^{-2} \mathrm{~s}^{-1}$. $B$. cinerea and $P$. syringae pv. tomato DC3000 avrRpml were inoculated as described by La Camera and associates. (2005). F1 plants modified for PLP2 expression and reacting with an HR to CMV were obtained by crossing the C24 ecotype with homozygous $P L P 2^{S I}$, empty-vector, or $P L P 2^{O E}$ Col-0 lines. CMV was multiplied in tobacco and purified according to Palukaitis and associates (1992). CMV was inoculated to Arabidopsis by gently rubbing fully expanded leaves with a glass spatula dipped in a solution of CMV at $5 \mu \mathrm{g} / \mathrm{ml}$ containing Carborundum. Tissue was harvested from inoculated leaves at indicated times and CMV content of uninoculated leaves was assayed in total rosettes harvested at 7 dpi after removal of all inoculated leaves.

For all experiments with vad1-1/PLP2 double mutants, plants were grown as previously described (Bouchez et al. 2007). Seedlings were transplanted 7 days after sowing to Jiffy pots and grown under a light period of $9 \mathrm{~h}\left(192 \mu \mathrm{mol} \mathrm{m} \mathrm{m}^{-2} \mathrm{~s}^{-1}\right)$ at $21^{\circ} \mathrm{C}$ and 40 to $70 \%$ humidity. Most experiments were performed with 5- to 6-week-old plants. Under these controlled conditions, lesions appeared on vadl-1 mutant 21 days after transplanting. Double mutants were obtained by crossing vad1-1 (pollen donor) and $P L P 2^{O E}$ or $P L P 2^{S I}$ lines already isolated (La Camera et al. 2005). F1 plants were selfed and homozygous vad1-1 plants were selected in the F2 progeny by PCR as described previously (Lorrain et al. 2004). For vad1$1 / P L P 2^{O E}$ lines presenting enhanced lesions compared with vad1-1, leaves without lesions were tested for PLP2 gene expression and compared with leaves from vad1-1, Ws, and Col0 at the same stage. Lines presenting strong expression were also validated by PLP2 immunodetection. In contrast, the vad1-1/PLP2 $2^{S I}$ double mutants presenting a strong reduction of lesions were tested for the absence of PLP2 transcript and PLP2 protein. Experiments were performed with F3- or F4-derived plants for each double mutant. Three double-mutant lines were analyzed out of four or five confirmed double -mutant lines. A vad1-1/pBIN double mutant was used as a control.

\section{CMV quantification and gene expression profiling.}

CMV content of leaf samples was determined by RNA blot analysis using standard procedures. Total RNA was isolated according to Dhondt and associates (2000) and separated on formaldehyde gels, transferred to Hybond $\mathrm{N}+$ membranes, and hybridized successively with radiolabeled cDNA probes corresponding to actin2 and then to the common $3^{\prime}$ end of viral RNAs 1 to 4 . Radioactive signals were quantified after exposure of blots to a phosphorimager plate. Because of the variability in virus multiplication in successive experiments, the sum of the signal recorded for control samples at day 3 was set to $100 \%$ for each independent batch of plants after normalization with actin 2 signal. Alternatively, CMV was quantified in C24 plants by real-time reverse-transcription (RT)-PCR as described below using primers matching the $3^{\prime}$ end sequence common to RNAs 1, 2, and 3.

For gene expression profiling by real-time RT-PCR, $1 \mu \mathrm{g}$ of total RNA was reverse transcribed using the ImProm-II reverse transcription system (Promega Corp., Madison, WI, U.S.A.) and oligo-dT. Quantitative RT-PCR was performed on $40 \mathrm{ng}$ of cDNA with the Mastermix Plus (SYBR green I; Eurogentec, Seraing, Belgium). Amplification of plant actin2 transcripts was used as a reference. The sequences of the gene-specific primer pairs used for PCR are given in Supplementary Table I. Primers for CMV detection are derived from the common region of viral RNAs 1, 2, and 3. PCR amplification was performed with an iCycler Optical System (Bio-Rad, Hercules, CA, U.S.A.) according to the manufacturer's instructions. Data were expressed relative to expression at day 0 in control plants.

For all experiments involving vadl-1 plants, total RNA extraction was performed with a Nucleospin RNA kit following the manufacturer's instructions (Macherey-Nagel, Hoerdt, France). Quantitative RT-PCR was performed using gene-specific primers for $P R I$ and $P D F 1-2$ as described by Bouchez and associates (2007). Gene At2g28390 encoding a SAND family protein was used as a reference because its expression was found extremely stable under different physiological conditions (Czechowski et al. 2005). Data are expressed as fold induction of each point compared with vadl-1 before lesion appearance (day 15). Experiments were repeated twice and were also analyzed with another housekeeping gene ( $\beta$-tubulin 4) yielding the same results (data not shown). Quantitative PCR was run on a Roche LightCycler system (Roche Diagnostics, Meylan, France) and performed using the SYBR GREEN I protocol according to the manufacturer's recommendations.

\section{Oxylipin profiling.}

Oxylipin analysis was performed as described, with some modifications (Göbel et al. 2003). For each experiment, $0.5 \mathrm{~g}$ of frozen leaves were extracted by adding $10 \mathrm{ml}$ of extraction medium (n-hexane: 2-propanol, 3:2 [ $\mathrm{vol} / \mathrm{vol}]$ with $0.0025 \%$ [wt/vol] butylated hydroxytoluene) and immediately homogenized with an Ultra Turrax homogenizer under streaming argon on ice for $30 \mathrm{~s}$. Prior to extraction, a mixture of internal standards was added: $100 \mathrm{ng}$ of $\mathrm{D}_{6}-\mathrm{JA}, 100 \mathrm{ng}$ of $\mathrm{D}_{5}$-OPDA, $500 \mathrm{ng}$ of $\mathrm{D}_{3}-2-\mathrm{HOT}, 50 \mu \mathrm{g}$ of heptadecanoic acid, and $13 \mathrm{~g}$ HOT. The extract was centrifuged at $3,200 \times g$ at $4^{\circ} \mathrm{C}$ for 10 min. The clear upper phase was dried under streaming nitrogen, redissolved in $1 \mathrm{ml}$ of isopropanol/chloroform (1:2 [ $\mathrm{vol} / \mathrm{vol}])$, and applied to an aminopropyl column (Supelclean $\mathrm{LC}-\mathrm{NH}_{2} 3-$ ml SPE tubes; Supelco, distributed by Sigma, Deisenhofen, Germany). Elution was performed with $6 \mathrm{ml}$ of 2-propanol/chloroform (1:2 [vol/vol] $), 9 \mathrm{ml}$ of diethyl ether/acetic acid $(98: 2[\mathrm{vol} / \mathrm{vol}])$, and $9 \mathrm{ml}$ of methanol/acetic acid (98:2 [vol/vol]). The last two eluates were separately dried under streaming nitrogen.

The residue of the diethylether-acetic acid eluate was redissolved in $200 \mu \mathrm{l}$ of methanol. For analysis of FA, $20 \mu \mathrm{l}$ of the fraction were methylated after addition of $380 \mu \mathrm{l}$ of methanol and $6.5 \mu \mathrm{l}$ of trimethylsilyldiazomethane (2 $\mathrm{M}$ in hexane; Sigma). After shaking for $30 \mathrm{~min}, 0.2 \mu \mathrm{l}$ of glacial acetic acid were added. The corresponding fatty acid methyl esters (FAME) were dried under streaming nitrogen and redissolved in $20 \mu \mathrm{l}$ of acetonitrile. The analysis of the FAME was performed with an Agilent (Waldbronn, Germany) 6890 gas chromatograph fitted with a capillary DB-23 column $(30 \mathrm{~m}$ by $0.25 \mathrm{~mm}, 0.25$ $\mu \mathrm{m}$ coating thickness; J\&W Scientific, Agilent). Helium was used as carrier gas $\left(1 \mathrm{ml} \mathrm{min}{ }^{-1}\right)$. The temperature gradient was $150^{\circ} \mathrm{C}$ for $1 \mathrm{~min}, 150$ to $200^{\circ} \mathrm{C}$ at $8 \mathrm{~K} \mathrm{~min}^{-1}, 200$ to $250^{\circ} \mathrm{C}$ at $25 \mathrm{~K} \mathrm{~min}^{-1}$, and $250^{\circ} \mathrm{C}$ for $6 \mathrm{~min}$. As internal standard for the quantification of FA, heptadecanoic acid was used. The remaining $180 \mu \mathrm{l}$ of the diethylether-acetic acid eluate were dried under streaming nitrogen and redissolved in $80 \mu \mathrm{l}$ of methanol/water/acetic acid (75:25:0.1 [vol/vol/vol]). Analysis of oxylipins was carried out on an Agilent 1100 HPLC system 
coupled to a diode array detector. At first, oxylipins were purified on reversed-phase (RP)-HPLC on an ET250/2 Nucleosil 120-5 C18 column ( 2.1 by $250 \mathrm{~mm}, 5-\mu \mathrm{m}$ particle size; Macherey-Nagel, Düren, Germany), with a solvent system of methanol/water/acetic acid (85:15:0.1 [ $\mathrm{vol} / \mathrm{vol} / \mathrm{vol}])$ and a flow rate of $0.18 \mathrm{ml} \mathrm{min}^{-1}$. For detection of hydroxy FA, absorbance at $234 \mathrm{~nm}\left(\mathrm{~A}_{234}\right)$, indicating the conjugated diene system, was recorded. Keto FA were detected by monitoring $A_{272} \mathrm{~nm}$. For quantification of the hydroxy and keto $\mathrm{FA}$, respectively, straight-phase HPLC was carried out on a Zorbax Rx-SIL column ( 2.1 by $150 \mathrm{~mm}, 5-\mu \mathrm{m}$ particle size; Agilent) with a solvent system of $n$-hexane:2-propanol:trifluoroacetic acid

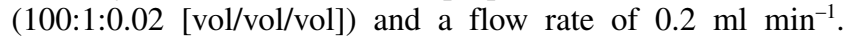
Oxylipins were quantified by using $13 \mathrm{~g}$-HOT as an internal standard to determine the recovery of the hydroxy FA and keto FA. Calibration curves (five-point measurements) for 13-HOD, 13-HOT, 13-KOD, and 13-KOT were established. For detection of JA, OPDA, and dinor-OPDA, these compounds were converted to their pentafluorobenzyl esters after purification by RP-HPLC according to Müller and Brodschelm (1994). The analysis was performed with a Finigan GCQ gas chromatography/mass spectrometry system equipped with a capillary Rtx-5 column (5\% diphenyl-95\% polydimethyl siloxane, $30 \mathrm{~m}$ by $0.25 \mathrm{~mm}, 0.25-\mu \mathrm{m}$ coating thickness; Restek, Fuldabrück, Germany). Helium was used as carrier gas $\left(0.7 \mathrm{ml} \mathrm{min}^{-1}\right)$. An electron energy of $70 \mathrm{eV}$, an ion source temperature of $200^{\circ} \mathrm{C}$, and a temperature of $300^{\circ} \mathrm{C}$ for the transfer line was used. The samples were measured in the negative chemical ionization mode using ammonia as ionization gas and the splitless injection mode (opened after $1 \mathrm{~min}$ ) with an injector temperature of $220^{\circ} \mathrm{C}$. The temperature gradient was $100^{\circ} \mathrm{C}$ for $1 \mathrm{~min}, 100$ to $300^{\circ} \mathrm{C}$ at $8 \mathrm{~K} \mathrm{~min}^{-1}$, and $300^{\circ} \mathrm{C}$ for $6 \mathrm{~min}$. For quantification, the ions $m / z 141\left(\mathrm{D}_{5}-\mathrm{SA} ; \mathrm{R}_{\mathrm{f}}=7.13 \mathrm{~min}\right), \mathrm{m} / z 137\left(\mathrm{SA} ; \mathrm{R}_{\mathrm{f}}=\right.$ $7.14 \mathrm{~min}), \mathrm{m} / z 215\left(\mathrm{D}_{6}-\mathrm{JA} ; \mathrm{R}_{\mathrm{f}}=11.26,11.67 \mathrm{~min}\right), \mathrm{m} / z 209$ $\left(\mathrm{JA} ; \mathbf{R}_{\mathrm{f}}=11.32,11.74 \mathrm{~min}\right.$ ), $m / z, 263$ (dinor-oPDA; $\mathbf{R}_{\mathrm{f}}=17.76$, 18.41, $18.95 \mathrm{~min}), \mathrm{m} / z, 296\left(\mathrm{D}_{5}\right.$-oPDA; $\mathrm{R}_{\mathrm{f}}=20.55,21.19$, $21.71 \mathrm{~min}$ ), and $\mathrm{m} / \mathrm{z} 291$ (oPDA; $\mathrm{R}_{\mathrm{f}}=20.61,21.24,21.76 \mathrm{~min}$ ) were used.

To detect 2-hydroxy FA in the methanol-acetic acid eluate, the residue of this fraction was methylated as described above. The corresponding methyl esters were redissolved in $5 \mu \mathrm{l}$ of acetonitrile. After addition of $1 \mu \mathrm{l}$ of pure N,O-bis(trimethylsilyl)trifluoroacetamide (Sigma), analysis of trimethylsilyl ethers of hydroxy FA methyl esters was carried out using an Agilent 5973 network mass selective detector connected to an Agilent 6890 gas chromatograph equipped with a capillary DB-23 column ( $30 \mathrm{~m}$ by $0.25 \mathrm{~mm} ; 0.25$ - $\mu \mathrm{m}$ coating thickness; J\&W Scientific, Agilent). Helium was used as a carrier gas at a flow rate of $1 \mathrm{ml} \mathrm{min}{ }^{-1}$. The temperature gradient was $150^{\circ} \mathrm{C}$ for $1 \mathrm{~min}, 150$ to $200^{\circ} \mathrm{C}$ at $4 \mathrm{~K} \mathrm{~min}^{-1}, 200$ to $250^{\circ} \mathrm{C}$ at $5 \mathrm{~K}$ $\mathrm{min}^{-1}$, and $250^{\circ} \mathrm{C}$ for $6 \mathrm{~min}$. Electron energy of $70 \mathrm{eV}$, an ion source temperature of $230^{\circ} \mathrm{C}$, and a temperature of $260^{\circ} \mathrm{C}$ for the transfer line were used. For quantification, the ions $m / z, 299$ $\left(2-\mathrm{HHA} ; \mathbf{R}_{\mathrm{f}}=6.75 \mathrm{~min}\right), \mathrm{m} / z 327\left(2-\mathrm{HOA} ; \mathbf{R}_{\mathrm{f}}=9.04 \mathrm{~min}\right), \mathrm{m} / \mathrm{z}$ 369 (2-HOE; $\left.\mathrm{R}_{\mathrm{f}}=9.42 \mathrm{~min}\right), \mathrm{m} / z 367\left(2-\mathrm{HOD} ; \mathrm{R}_{\mathrm{f}}=10.18\right.$ $\mathrm{min}), m / z, 324\left(\mathrm{D}_{3}-2-\mathrm{HOT} ; \mathrm{R}_{\mathrm{f}}=11.11 \mathrm{~min}\right)$, and $\mathrm{m} / z, 321(2-$ HOT; $R_{f}=11.13 \mathrm{~min}$ ) were used. Standard curves were constructed by analyzing known mixtures of unlabeled 2-hydroxy FA and $\mathrm{D}_{3}$-2-HOT and plotting the ratios of ion intensities (ion of unlabeled/ion of deuterium-labeled) versus the molar amount of unlabeled.

\section{ACKNOWLEDGMENTS}

This work and S. La Camera were initially supported by the French Génoplante programme. We thank R. Wagner, A. Bailly, M. Kerneis, S. Staerck, and C. Chauveau for producing the numerous plants used in this study; M. Alioua for help in initial real-time RT-PCR experiments; and P. Palukaitis (Scottish Crop Research Institute, Dundee, U.K.) for providing the $\mathrm{CMV}(\mathrm{Y})$ strain and $\mathrm{cDNA}$ probe.

\section{LITERATURE CITED}

AbuQamar, S., Chen, X., Dhawan, R., Bluhm, B., Salmeron, J., Lam, S., Dietrich, R. A., and Mengiste, T. 2006. Expression profiling and mutant analysis reveals complex regulatory networks involved in Arabidopsis response to Botrytis infection. Plant J. 48:28-44.

Andersson, M. X., Hamberg, M., Kourtchenko, O., Brunnstrom, A., McPhail, K. L., Gerwick, W. H., Gobel, C., Feussner, I., and Ellerstrom, M. 2006. Oxylipin profiling of the hypersensitive response in Arabidopsis thaliana. Formation of a novel oxo-phytodienoic acid-containing galactolipid, arabidopside Eur. J. Biol. Chem. 281:31528-31537.

Bargmann, B. O., and Munnik, T. 2006. The role of phospholipase D in plant stress responses. Curr. Opin. Plant Biol. 9:515-522.

Bouchez, O., Huard, C., Lorrain, S., Roby, D., and Balague, C. 2007. Ethylene is one of the key elements for cell death and defense response control in the Arabidopsis lesion mimic mutant vad1. Plant Physiol. 145:465-477.

Buseman, C. M., Tamura, P., Sparks, A. A., Baughman, E. J., Maatta, S. Zhao, J., Roth, M. R., Esch, S. W., Shah, J., Williams, T. D., and Welti, R. 2006. Wounding stimulates the accumulation of glycerolipids containing oxophytodienoic acid and dinor-oxophytodienoic acid in Arabidopsis leaves. Plant Physiol. 142:28-39.

Cacas, J. L., Vailleau, F., Davoine, C., Ennar, N., Agnel, J. P., Tronchet, M., Ponchet, M., Blein, J. P., Roby, D., Triantaphylides, C., and Montillet, J. L. 2005. The combined action of 9 lipoxygenase and galactolipase is sufficient to bring about programmed cell death during tobacco hypersensitive response. Plant Cell Environ. 28:1367-1378.

Costet, L., Cordelier, S., Dorey, S., Baillieul, F., Fritig, B., and Kauffmann, S. 1999. Relationship between localized acquired resistance (LAR) and the hypersensitive response (HR): HR is necessary for LAR to occur and salicylic acid is not sufficient to trigger LAR. Mol. Plant-Microbe Interact. 12:655-662.

Czechowski, T., Stitt, M., Altmann, T., Udvardi, M. K., and Scheible, W. R. 2005. Genome-wide identification and testing of superior reference genes for transcript normalization in Arabidopsis. Plant Physiol. 139:5-17.

Dahiya, P. 2003. Role of death in providing lifeline to plants. Trends Plant Sci. 8:462-465.

De Leon, I. P., Sanz, A., Hamberg, M., and Castresana, C. 2002. Involvement of the Arabidopsis alpha-DOX1 fatty acid dioxygenase in protection against oxidative stress and cell death. Plant J. 29:61-62.

Dhondt, S., Geoffroy, P., Stelmach, B. A., Legrand, M., and Heitz, T. 2000. Soluble phospholipase A2 activity is induced before oxylipin accumulation in Tobacco mosaic virus-infected tobacco leaves and is contributed by patatin-like enzymes. Plant J. 23:431-440.

Dhondt, S., Gouzerh, G., Muller, A., Legrand, M., and Heitz, T. 2002. Spatio-temporal expression of patatin-like lipid acyl hydrolases and accumulation of jasmonates in elicitor-treated tobacco leaves are not affected by endogenous levels of salicylic acid. Plant J. 32:749-762.

Dong, X. 2004. The role of membrane-bound ankyrin-repeat protein ACD6 in programmed cell death and plant defense. Sci. STKE 2004:pe6.

Duan, H., Huang, M. Y., Palacio, K., and Schuler, M. A. 2005. Variations in CYP74B2 (hydroperoxide lyase) gene expression differentially affect hexenal signaling in the Columbia and Landsberg erecta ecotypes of Arabidopsis. Plant Physiol. 139:1529-1544.

Feussner, I., and Wasternack, C. 2002. The lipoxygenase pathway. Annu. Rev. Plant Biol. 53:275-297.

Glazebrook, J. 2005. Contrasting mechanisms of defense against biotrophic and necrotrophic pathogens. Annu. Rev. Phytopathol. 43:205-227.

Göbel, C., Feussner, I., Hamberg, M., and Rosahl, S. 2002. Oxylipin profiling in pathogen-infected potato leaves. Biochim. Biophys. Acta. 1584:55-64.

Göbel, C., Feussner, I., and Rosahl, S. 2003. Lipid peroxidation during the hypersensitive response in potato in the absence of 9-lipoxygenases. J. Biol. Chem. 278:52834-52840.

Greenberg, J. T., and Yao, N. 2004. The role and regulation of programmed cell death in plant-pathogen interactions. Cell Microbiol. 6:201-211.

Hamberg, M., Sanz, A., Rodriguez, M. J., Calvo, A. P., and Castresana, C. 2003. Activation of the fatty acid alpha-dioxygenase pathway during bacterial infection of tobacco leaves. Formation of oxylipins protecting against cell death. J. Biol. Chem. 278:51796-51805.

Hamberg, M., Ponce de Leon, I., Rodriguez, M. J., and Castresana, C. 2005. Alpha-dioxygenases. Biochem. Biophys. Res. Commun. 338:169-174

Hatsugai, N., Kuroyanagi, M., Yamada, K., Meshi, T., Tsuda, S., Kondo, M., Nishimura, M., and Hara-Nishimura, I. 2004. A plant vacuolar pro- 
tease, VPE, mediates virus-induced hypersensitive cell death. Science 305:855-858

Holk, A., Rietz, S., Zahn, M., Quader, H., and Scherer, G. F. 2002. Molecular identification of cytosolic, patatin-related phospholipases A from Arabidopsis with potential functions in plant signal transduction. Plant Physiol. 130:90-101.

Hong, J. K., Choi, H. W., Hwang, I. S., Kim, D. S., Kim, N. H., Choi du, S., Kim, Y. J., and Hwang, B. K. 2008. Function of a novel GDSL-type pepper lipase gene, CaGLIP1, in disease susceptibility and abiotic stress tolerance. Planta 227:539-558.

Howe, G. A., and Schilmiller, A. L. 2002. Oxylipin metabolism in response to stress. Curr. Opin. Plant Biol. 5:230-236.

Hyun, Y., Choi, S., Hwang, H. J., Yu, J., Nam, S. J., Ko, J., Park, J. Y., Seo, Y. S., Kim, E. Y., Ryu, S. B., Kim, W. T., Lee, Y. H., Kang, H., and Lee, I. 2008. Cooperation and functional diversification of two closely related galactolipase genes for jasmonate biosynthesis. Dev. Cell 14:183-192.

Imani, J., Baltruschat, H., Stein, H., Jia, G., Vogelsberg, J., Kogel, K.-H., and Hückelhoven, R. 2006. Expression of BAX Inhibitor-1 in carrots confers resistance to Botrytis cinerea. Mol. Plant Pathol. 7:279-284.

Ishiguro, S., Kawai-Oda, A., Ueda, J., Nishida, I., and Okada, K. 2001. The DEFECTIVE IN ANTHER DEHISCENCE gene encodes a novel phospholipase A1 catalyzing the initial step of jasmonic acid biosynthesis, which synchronizes pollen maturation, anther dehiscence, and flower opening in Arabidopsis. Plant Cell 13:2191-2209.

Jakab, G., Manrique, A., Zimmerli, L., Metraux, J. P., and Mauch-Mani, B 2003. Molecular characterization of a novel lipase-like pathogen-inducible gene family of Arabidopsis. Plant Physiol. 132:2230-2239.

Jones, A. M. 2001. Programmed cell death in development and defense. Plant Physiol. 125:94-97.

Kuroyanagi, M., Yamada, K., Hatsugai, N., Kondo, M., Nishimura, M., and Hara-Nishimura, I. 2005. Vacuolar processing enzyme is essential for mycotoxin-induced cell death in Arabidopsis thaliana. J. Biol. Chem. 280:32914-32920.

La Camera, S., Gouzerh, G., Dhondt, S., Hoffmann, L., Fritig, B., Legrand M., and Heitz, T. 2004. Metabolic reprogramming in plant innate immunity: The contributions of phenylpropanoid and oxylipin pathways. Immunol. Rev. 198:267-284.

La Camera, S., Geoffroy, P., Samaha, H., Ndiaye, A., Rahim, G., Legrand, M., and Heitz, T. 2005. A pathogen-inducible patatin-like lipid acyl hydrolase facilitates fungal and bacterial host colonization in Arabidopsis. Plant J. 44:810-825

Laurie-Berry, N., Joardar, V., Street, I. H., and Kunkel, B. N. 2006. The Arabidopsis thaliana JASMONATE INSENSITIVE 1 gene is required for suppression of salicylic acid-dependent defenses during infection by Pseudomonas syringae. Mol. Plant-Microbe Interact. 19:789-800.

Lee, H. Y., Bahn, S. C., Shin, J. S., Hwang, I., Back, K., Doelling, J. H., and Ryu, S. B. 2005. Multiple forms of secretory phospholipase A2 in plants. Progr. Lipid Res. 44:52-67.

Liavonchanka, A., and Feussner, I. 2006. Lipoxygenases: Occurrence, functions and catalysis. J. Plant Physiol. 163:348-357.

Lorrain, S., Vailleau, F., Balague, C., and Roby, D. 2003. Lesion mimic mutants: Keys for deciphering cell death and defense pathways in plants? Trends Plant Sci. 8:263-271.

Lorrain, S., Lin, B., Auriac, M. C., Kroj, T., Saindrenan, P., Nicole, M., Balague, C., and Roby, D. 2004. Vascular associated death 1, a novel GRAM domain-containing protein, is a regulator of cell death and defense responses in vascular tissues. Plant Cell 16:2217-2232.

Montillet, J. L., Agnel, J. P., Ponchet, M., Vailleau, F., Roby, D., and Triantaphylides, C. 2002. Lipoxygenase-mediated production of fatty acid hydroperoxides is a specific signature of the hypersensitive reaction in plants. Plant Physiol. Biochem. 40:633-639.

Mueller, M. J., and Brodschelm, W. 1994. Quantification of jasmonic acid by capillary gas chromatography-negative chemical ionization-mass spectrometry. Anal. Biochem. 218:425-435.

Mur, L. A., Kenton, P., Lloyd, A. J., Ougham, H., and Prats, E. 2008. The hypersensitive response; the centenary is upon us but how much do we know? J. Exp. Bot. 59:501-520.

Oh, I. S., Park, A. R., Bae, M. S., Kwon, S. J., Kim, Y. S., Lee, J. E., Kang, N. Y., Lee, S., Cheong, H., and Park, O. K. 2005. Secretome analysis reveals an Arabidopsis lipase involved in defense against Alternaria brassicicola. Plant Cell 17:2832-2847.

Oliver, R., and Ipcho, S. 2004. Arabidopsis pathology breathes new life into the necrotrophs-vs.-biotrophs classification of fungal pathogens. Mol. Plant Pathol. 5:347-352.

Palukaitis, P., Roossinck, M. J., Dietzgen, R. G., and Francki, R. I. 1992. Cucumber mosaic virus. Adv. Virus Res. 41:281-348.

Prost, I., Dhondt, S., Rothe, G., Vicente, J., Rodriguez, M. J., Kift, N.,
Carbonne, F., Griffiths, G., Esquerre-Tugaye, M. T., Rosahl, S., Castresana, C., Hamberg, M., and Fournier, J. 2005. Evaluation of the antimicrobial activities of plant oxylipins supports their involvement in defense against pathogens. Plant Physiol. 139:1902-1913.

Raffaele, S., Rivas, S., and Roby, D. 2006. An essential role for salicylic acid in AtMYB30-mediated control of the hypersensitive cell death program in Arabidopsis. FEBS (Fed. Eur. Biol. Soc.) Lett. 580:3498-3504.

Raffaele, S., Vailleau, F., Leger, A., Joubes, J., Miersch, O., Huard, C., Blee, E., Mongrand, S., Domergue, F., and Roby, D. 2008. A MYB transcription factor regulates very-long-chain fatty acid biosynthesis for activation of the hypersensitive cell death response in Arabidopsis. Plant Cell 20:752767.

Rairdan, G. J., and Delaney, T. P. 2002. Role of salicylic acid and NIM1/ NPR1 in race-specific resistance in Arabidopsis. Genetics 161:803-811.

Rojo, E., Martin, R., Carter, C., Zouhar, J., Pan, S., Plotnikova, J., Jin, H., Paneque, M., Sanchez-Serrano, J. J., Baker, B., Ausubel, F. M., and Raikhel, N. V. 2004. VPEgamma exhibits a caspase-like activity that contributes to defense against pathogens. Curr. Biol. 14:1897-1906.

Rusterucci, C., Montillet, J. L., Agnel, J. P., Battesti, C., Alonso, B., Knoll, A., Bessoule, J. J., Etienne, P., Suty, L., Blein, J. P., and Triantaphylides, C. 1999. Involvement of lipoxygenase-dependent production of fatty acid hydroperoxides in the development of the hypersensitive cell death induced by cryptogein on tobacco leaves. J. Biol. Chem. 274:3644636455.

Ryu, S. B. 2004. Phospholipid-derived signaling mediated by phospholipase A in plants. Trends Plant Sci. 9:229-235.

Shah, J. 2005. Lipids, lipases, and lipid-modifying enzymes in plant disease resistance. Annu. Rev. Phytopathol. 43:229-260.

Staswick, P. E., Yuen, G. Y., and Lehman, C. C. 1998. Jasmonate signaling mutants of Arabidopsis are susceptible to the soil fungus Pythium irregulare. Plant J. 15:747-754.

Takahashi, H., Goto, N., and Ehara, Y. 1994. Hypersensitive response in cucumber mosaic virus-inoculated Arabidopsis thaliana. Mol. PlantMicrobe Interact. 6:369-377.

Takahashi, H., Miller, J., Nozaki, Y., Takeda, M., Shah, J., Hase, S. Ikegami, M., Ehara, Y., and Dinesh-Kumar, S.P. 2002. RCY1, an Arabidopsis thaliana RPP8/HRT family resistance gene, conferring resistance to cucumber mosaic virus requires salicylic acid, ethylene and a novel signal transduction mechanism. Plant J. 32:655-667.

Thoma, I., Krischke, M., Loeffler, C., and Mueller, M. J. 2004. The isoprostanoid pathway in plants. Chem. Phys. Lipids. 128:135-148.

Thomma, B. P., Eggermont, K., Penninckx, I. A., Mauch-Mani, B., Vogelsang, R., Cammue, B. P., and Broekaert, W. F. 1998. Separate jasmonate-dependent and salicylate-dependent defense-response pathways in Arabidopsis are essential for resistance to distinct microbial pathogens. Proc. Natl. Acad. Sci. U.S.A. 95:15107-15111.

Vailleau, F., Daniel, X., Tronchet, M., Montillet, J. L., Triantaphylides, C., and Roby, D. 2002. A R2R3-MYB gene, AtMYB30, acts as a positive regulator of the hypersensitive cell death program in plants in response to pathogen attack. Proc. Natl. Acad. Sci. U.S.A. 99:10179-10184.

Vellosillo, T., Martinez, M., Lopez, M. A., Vicente, J., Cascon, T., Dolan, L., Hamberg, M., and Castresana, C. 2007. Oxylipins produced by the 9-lipoxygenase pathway in Arabidopsis regulate lateral root development and defense responses through a specific signaling cascade. Plant Cell. 19:831-846.

Vijayan, P., Shockey, J., Levesque, C. A., Cook, R. J., and Browse, J. 1998. A role for jasmonate in pathogen defense of Arabidopsis. Proc. Natl. Acad. Sci. U.S.A. 95:7209-7214.

Vollenweider, S., Weber, H., Stolz, S., Chetelat, A., and Farmer, E. E. 2000. Fatty acid ketodienes and fatty acid ketotrienes: Michael addition acceptors that accumulate in wounded and diseased Arabidopsis leaves. Plant J. 24:467-476.

Wasternack, C. 2007. Jasmonates: An update on biosynthesis, signal transduction and action in plant stress response, growth and development. Ann. Bot. (Lond.) 100:681-697.

Weber, H. 2002. Fatty acid-derived signals in plants. Trends Plant Sci. 7:217-224.

Yang, W., Devaiah, S. P., Pan, X., Isaac, G., Welti, R., and Wang, X. 2007. AtPLAI is an acyl hydrolase involved in basal jasmonic acid production and Arabidopsis resistance to Botrytis cinerea. J. Biol. Chem. 282:1811618128.

\section{AUTHOR-RECOMMENDED INTERNET RESOURCE}

Genevestigator, a reference expression database and meta-analysis system: www.genevestigator.ethz.ch 